\title{
Estudo Multidisciplinar (Geoquímica e Associações de Foraminíferos) para Caracterizar e Avaliar Intervenções Antrópicas na Baía do Araçá, Canal de São Sebastião, SP
}

\section{Multidisciplinary Study (Geochemical and Foraminiferal Assemblages) to Characterize and Assess Anthropic Activities at the Araçá Bay, São Sebastião Channel, Brazil}

\author{
Andreia Cristiane Teodoro' (andreia.teodoro@usp.br),Wânia Duleba1,2 (wduleba@usp.br), \\ Silas Gubitoso' (silas.gubitoso@usp.br) \\ 'Departamento de Geologia Sedimentar e Ambiental - Instituto de Geociências - USP \\ R. do Lago 562, CEP 05508-080, São Paulo, SP, BR \\ ${ }^{2}$ Escola de Artes, Ciências e Humanidades - USP Leste, São Paulo, SP, BR
}

Recebido em 21 de maio de 2010; aceito em 01 de fevereiro de 2011

\section{RESUMO}

O objetivo deste estudo foi avaliar possíveis alterações ambientais, decorrentes de aporte de esgoto doméstico, na Baía do Araçá, Canal de São Sebastião, SP. Para atingir tal objetivo foram realizadas análises granulométricas, geoquímicas (Cot, N, $\mathrm{S}$ e P) e das associações de foraminíferos de sedimentos marinhos superficiais, coletados ao redor dos difusores do emissário submarino de esgotos domésticos do Araçá, em Abril de 2006. De acordo com os resultados obtidos a região estudada é constituída de sedimentos litoclásticos, predominantemente arenosos. Contudo, na porção nordeste da área de estudo, há ocorrência de elevadas concentrações de sedimentos finos (silte e argila), com significativas concentrações de Cot $(>1 \%), \mathrm{N}(>0,20 \%)$ e S $(>0,3 \%)$. O enriquecimento orgânico que ocorre na área de estudo é evidenciado, principalmente, pelas concentrações de fósforo, de enxofre, assim como pelo potencial de oxirredução, inferido por meio dos valores de Eh e razões C/S. No tocante às associações de foraminíferos bentônicos, observou-se baixa riqueza, com predominância de espécies infaunais e detritívoras. Espécies epifaunais, bioindicadoras de ambiente bem oxigenado, estão concentradas em estações sem influência do esgoto disposto pelo emissário submarino. A presença de foraminíferos com carapaças médias e pequenas está, qualitativamente, associada a condições de menor oxigenação no compartimento bentônico. A dominância de somente uma espécie (Ammonia tepida), em toda a área de estudo, corrobora o estresse ambiental evidenciado pelos demais parâmetros bióticos e abióticos.

Palavras-chave: Baía do Araçá; Geoquímica; Foraminíferos bentônicos; Esgoto doméstico; Emissário submarino.

\begin{abstract}
The goal of this study was to assess possible human-induced changes in the environment due to the discharge of domestic sewage into the Araçá Bay, São Sebastião Channel, São Sebastião, Brazil. In order to achieve this goal, in April 2006, we conducted grain size and geochemical (Toc, N, S, and P) analysis and determined the assemblage composition and distribution of live benthic foraminifera from shallow marine sediments collected around diffusers of the domestic sewage submarine outfall at the Araçá Bay. Results showed that the area studied is a lithoclastic shallow environment with predominance of sandy sediments. However, in the northeastern area of the sampling grid, it was observed high concentrations of fine sediments (silt plus clay), with significant Toc $(>1 \%), \mathrm{N}(>0.2 \%)$ and $\mathrm{S}(0.3 \%)$ contents. The organic enrichment is inferred based on the phosphorus and sulphur contents, as well as on the oxidation-reduction potential, which was inferred using the Eh values and $\mathrm{C} / \mathrm{S}$ ratios. In relation to the benthic foraminiferal assemblages, low richness was observed and the association is mainly composed of infaunal and detritivore species. There is a high abundance of Epifaunal species, which are bioindicators of well-oxygenated environments, in stations with no impact of the sewage discharged by submarine outfall. The occurrence of medium and small-sized foraminifera shells is qualitatively associated with low oxygen concentrations at the sediment-water interface. The dominance of a few species, especially Ammonia tepida, may indicate environmental stress.
\end{abstract}

Keywords: Araçá Bay; Geochemical; Benthic foraminifera; Domestic sewage; Submarine outfall. 


\section{INTRODUÇÃO}

Ambientes marinhos costeiros possuem complexas variações nos parâmetros físico-químicos, o que em muitas ocasiões, tende a dificultar sua caracterização. Além do fato de serem regiões cujos parâmetros abióticos alteram-se de forma natural diariamente (e.g. ciclos de marés), são ambientes sujeitos a diversos tipos de intervenções antrópicas, sejam elas ocasionadas por fontes difusas ou pontuais de estresse ambiental.

Muitos pesquisadores têm utilizado a geoquímica em conjunto com a análise da comunidade de organismos pertencentes à meiofauna (bioindicadores) para elucidar e caracterizar a origem e o grau de alteração ambiental em locais sob influência de estressores antrópicos, e.g. disposição oceânica de efluentes domésticos (Armynot du Châtelet, Debenay, Soulard, 2004; Burone et al., 2006; Debenay e Fernandez, 2009).

De acordo com as propriedades geoquímicas dos sedimentos, podem-se inferir fontes de aporte de matéria orgânica e o grau de estresse ambiental. A utilização de bioindicadores, por sua vez, parte da premissa de que determinados organismos (espécies, grupos de espécies e comunidades biológicas) corroboram para elucidar fenômenos, eventos naturais e/ou antrópicos, que ocorrem nos ecossistemas, sejam estes temporais e/ou espaciais (Boltovskoy, 1959).

Embora não estejam incluídos em protocolos oficiais de agências governamentais para caracterizações ambientais (Debenay e Fernandez, 2009), os foraminíferos têm sido considerados excelentes bioindicadores por possuírem curto ciclo de vida e elevada sensibilidade a alterações físico-químicas no ambiente. Além disso, são abundantes, diversificados taxonomicamente e sua amostragem causa impacto mínimo ao meio ambiente (Yanko, Kronfeld, Flexer, 1994; Alve, 1995).

Zalesny (1959) e Resig (1960) foram os primeiros autores a realizarem trabalhos utilizando foraminíferos como bioindicadores. A partir de então, muitos outros trabalhos foram realizados para caracterização de influências antrópicas, sejam elas devido ao aporte, em ambiente marinho, de esgotos domésticos e industriais, metais pesados e hidrocarbonetos (Alve, 1995; Cearreta et al., 2002; Burone et al., 2006; Frontalini et al., 2009, entre outros).

A Baía do Araçá, localizada no Canal de São Sebastião, SP, tal qual as demais regiões litorâneas, é sujeita a diversos tipos de intervenções antrópicas, dentre elas o turismo e o porto de São Sebastião, o qual recebe embarcações de pequeno e médio calado, bem como a disposição oceânica de esgotos domésticos, por meio de emissário submarino. O emissário da Baía do Araçá está em operação desde 1990, atende a uma população média de 21.200 habitantes, e apresenta vazão média de $201 \mathrm{~m}^{3} /$ dia (CETESB, 2007). A parte submarina, a qual se inicia na praia, tem extensão de $1.090 \mathrm{~m}$ e possui um trecho difusor com 17 orifícios, os quais estão distribuídos nos últimos $10 \mathrm{~m}$ de comprimento (CETESB, 2007).

O efluente, derivado de esgotos domésticos e águas pluviais, na estação de pré-condicionamento (EPC), recebe somente tratamento preliminar, o qual consiste na passagem por peneiras estáticas e caixas de areia, e posterior desinfecção por cloração. Após o tratamento preliminar o efluente é disposto no ambiente marinho (CETESB op. cit.).

Mediante ao acima exposto, o presente estudo tem por objetivo verificar se a disposição oceânica de esgotos domésticos, a qual ocorre através do emissário submarino do Araçá, produz alterações na geoquímica e na composição das associações de foraminíferos bentônicos na região próxima aos difusores.

\section{ÁREA DE ESTUDO}

O Canal de São Sebastião (CSS) localiza-se entre as latitudes $23^{\circ} 40^{\prime}$ e $23^{\circ} 53,5^{\prime} \mathrm{S}$ e longitudes $45^{\circ} 19^{\prime}$ e $45^{\circ} 30 \mathrm{~W}$, litoral norte do Estado de São Paulo (Figura 1).

A extensão do CSS é de aproximadamente $25 \mathrm{~km}$, com largura variando entre $6 \mathrm{~km}$ na entrada norte e $7 \mathrm{~km}$ na entrada sul. A região central do canal é a mais estreita, possui aproximadamente $2 \mathrm{~km}$ de largura.

A circulação hídrica no CSS possui comportamento sazonal (Fontes, 1995; Castro-Filho et al., 2008). No verão ocorre circulação em duas camadas; a superficial em direção sudoeste e a profunda para noroeste, sendo esta associada à intrusão da Água Central do Attântico Sul (ACAS) pela extremidade sul. No outono, inverno e primavera a circulação é barotrópica caracterizada por fluxo unidirecional em sentido NE (Silva, Miranda, Castro, 2001). Nestes períodos, são atuantes a Água Costeira (AC) e Água Tropical (AT). As correntes de superfície são consideradas intensas, com velocidade média oscilando entre $0,7 \mathrm{e}$ 1,0 $\mathrm{m} \mathrm{s}^{-1}$, em sentido de SW para NE (FUNDESPA, 1999), podendo, entretanto, haver rápida inversão de direção das correntes superficiais, caso haja alternância na direção dos ventos (Miranda e Castro-Filho, 1995).

A Baía do Araçá localiza-se na plataforma continental interna, região central do CSS, entre as latitudes $23^{\circ} 48^{\prime}$ e $23^{\circ} 49^{\prime} \mathrm{S}$ e longitudes $45^{\circ} 23,9^{\prime}$ e $45^{\circ} 24^{\prime} \mathrm{W}$. Trata-se de uma baía artificial formada durante a construção do Porto de São Sebastião, em 1936 (CAP, 2009). A profundidade máxima no interior da baía é de $10 \mathrm{~m}$, com marés que oscilam entre +2,06 m (máxima), -0,04 m (mínima) e nível intermediário de $+1,15 \mathrm{~m}$ (Marcellino, 2000).

Em relação à composição textural dos sedimentos, na área de estudo, próximo a Ponta do Araçá, ocorre distribui- 


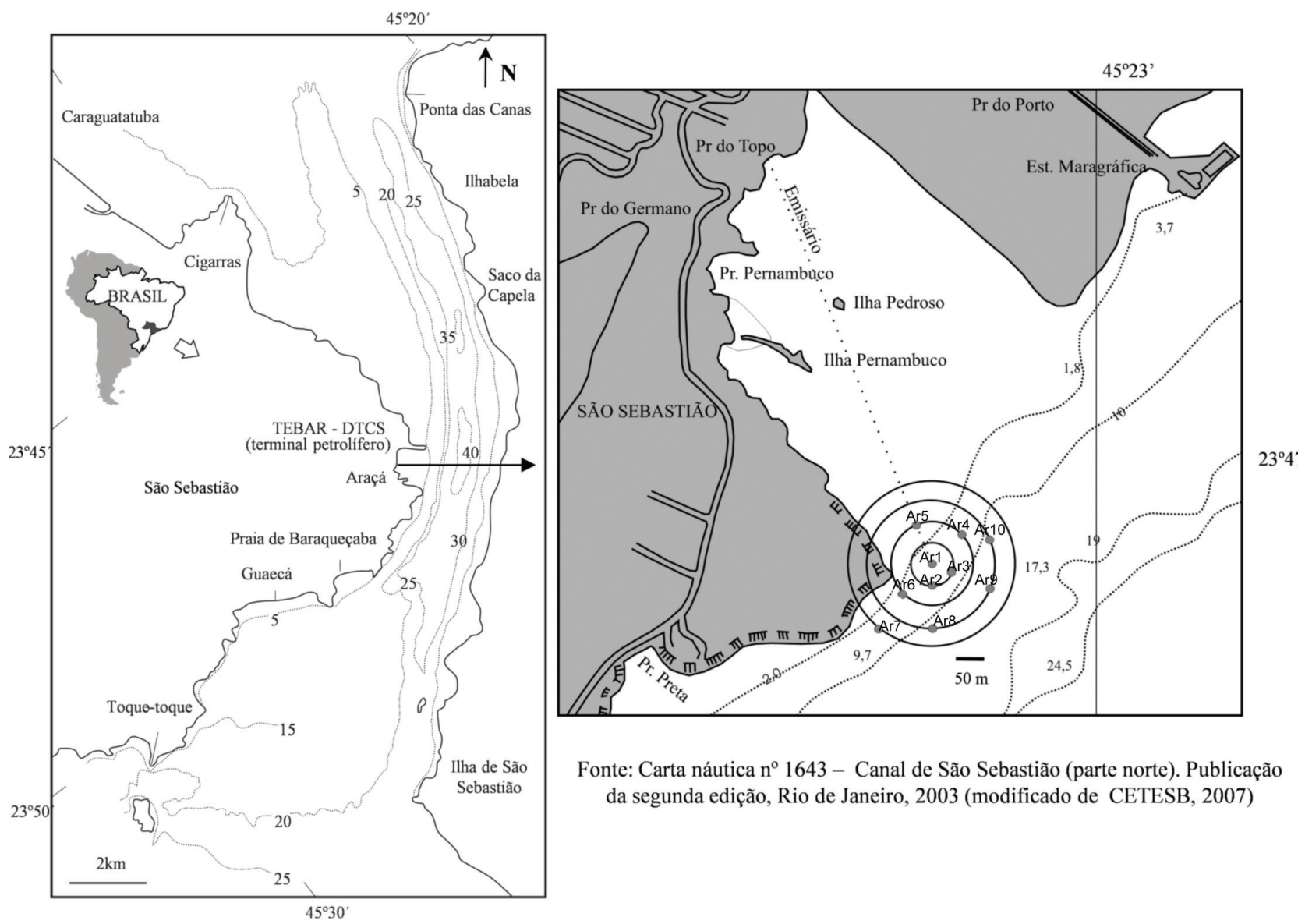

Figura 1. Localização do Canal de São Sebastião e malha de amostragem.

ção de forma heterogênea, em manchas, sendo, entretanto, predominantes sedimentos arenosos, fração areia média a grossa (Conti, 1998). No interior da baía, por sua vez, observa-se composição textural variando entre silte e areia muito fina (Conti, 1998; Barcellos, 2000).

\section{MATERIAL E MÉTODOS}

Foram coletadas dez amostras de sedimento em região próxima aos difusores do emissário submarino, em Abril de 2006. A malha de amostragem utilizada foi em círculos concêntricos, espaçados entre si a cada $50 \mathrm{~m}$ (Figura 1). A primeira estação foi posicionada na saída do emissário submarino, sendo as demais estações distribuídas em área de aproximadamente $500 \mathrm{~m}^{2}$, circunjacente a área de maior influência da disposição oceânica (i.e. região dos difusores).

Em cada estação, nas águas de fundo, foram obtidos dados de temperatura, salinidade e oxigênio dissolvido por meio de sonda CTD SeaCat. Os parâmetros pH e turbidez, também analisados nas águas de fundo, foram obtidos por analisador de $\mathrm{pH}$ - Beckman Zeromatic II, sendo o parâmetro turbidez obtido pelo método Nefelométrico. As análises da coluna d'água foram realizadas e cedidas pela Companhia Ambiental do Estado de São Paulo (CETESB).

As amostras de sedimento de superfície, coletadas por pegador do tipo Petersen, foram divididas em três subamostras para as análises: 1. granulométricas, 2. geoquímicas e 3. determinação das associações de foraminíferos bentônicos (vivos). As amostras para as análises geoquímicas foram preservadas congeladas, com o intuito de evitar degradação bacteriana.

\section{Análises granulométricas e geoquímicas}

A análise granulométrica foi realizada por meio de metodologia padrão de pipetagem (fração $<0,062 \mathrm{~mm}$ ) e peneiramento (fração entre 0,062 e $2 \mathrm{~mm}$ ), descrita em Su- 
guio (1973). A composição textural e o grau de seleção foram classificados de acordo com o proposto em Shepard (1954) e Folk e Ward (1957), respectivamente.

Foram realizadas análises dos teores de carbonato de cálcio $\left(\mathrm{CaCO}_{3}\right)$, de carbono orgânico total (Cot), de nitrogênio total $(\mathrm{N})$, de fósforo total, orgânico e inorgânico (Ptotal, Porg e Pinorg) e de enxofre total (S). Os teores de $\mathrm{CaCO}_{3}$ foram obtidos pela diferença de massa após dissolução ácida em $\mathrm{HCl}$ a $10 \%$ (Gross, 1971). As concentrações de Cot e $\mathrm{N}$ foram obtidas por meio do analisador CHN-1000 e as concentrações de $\mathrm{S}$ pelo analisador SC-432, ambos da LECO $^{\circledR}$. As análises de Ptotal e Pinorg foram feitas pelo método espectrofotométrico de ácido ascórbico (Legg e Black, 1955), com adaptação para sistema de análise de injeção de fluxo (Zagatto et al., 1981). Os teores de Porg, por sua vez, foram obtidos pela diferença de concentração entre Ptotal e Pinorg.

Com base nos resultados obtidos para as análises de Cot, $\mathrm{N}$ e S, foram calculadas razões elementares para identificar a origem da matéria orgânica (razões $\mathrm{C} / \mathrm{N}$ ) e o potencial de oxirredução dos sedimentos (razões C/S).

\section{Análise dos foraminíferos}

Para o estudo dos foraminíferos bentônicos vivos, somente a camada superior $(5 \mathrm{~cm})$ de sedimento, sem sinais de mistura com camadas de subsuperfície, foi amostrada em cada estação. Os sedimentos de superfície foram obtidos por amostrador do tipo Petersen, com área de amostragem de $20 \mathrm{~cm}^{2}$.

Imediatamente após a amostragem, os sedimentos foram preservados em álcool $70 \mathrm{GL}$ e corados com Rosa de Bengala, para distinguir entre espécimes vivos e mortos no momento da coleta (Walton, 1952).

Em laboratório, devido à baixa densidade de foraminíferos bentônicos vivos, alíquotas de $10 \mathrm{~cm}^{3}$ de sedimento foram triadas, em sua totalidade, até a obtenção de no mínimo 100 foraminíferos vivos, número considerado viável para análises estatísticas (Murray, 1991).

Os foraminíferos foram separados do sedimento por flutuação-decantação em tricloroetileno $\left(\mathrm{CCl}_{4}\right)$. Os resíduos da análise densimétrica foram posteriormente analisados sob lupa estereoscópica para evitar perda de espécimes mais pesados, que, porventura, não foram decantados.

Posteriormente, a classificação taxonômica baseou-se no Atlas de Foraminíferos do Atlântico Sul, elaborado por Boltovskoy et al. (1980).

No tocante a análise morfométrica, realizada em todas as carapaças de foraminíferos triadas, foi utilizado o programa de análise de imagens AnalySis 5 (Soft Imaging System Corp.). De acordo com os resultados obtidos, as carapaças foram divididas em três classes de tamanho: pe- quenas $(<125 \mu \mathrm{m})$, médias $(125$ a $250 \mu \mathrm{m})$ e grandes $(250$ a $500 \mu \mathrm{m})$. A definição das classes de tamanho foi baseada na escala granulométrica proposta por Wentworth (1922), respectivamente para areia fina, média e grossa.

Considerando que foraminíferos bentônicos respondem sensivelmente a mudanças nas variáveis abióticas (i.e., aumento do fluxo de matéria orgânica, nível de oxigenação e hidrodinamismo), as espécies identificadas foram divididas em dois grupos: espécies bioindicadoras de ambiente enriquecido por matéria orgânica (Apêndice 1.1) e espécies bioindicadoras de ambiente bem oxigenado (Apêndice 1.2). O uso de foraminíferos bentônicos como proxie qualitativo para analisar enriquecimento orgânico e nível de oxigenação foi principalmente baseado em Kaiho (1994) e Duleba et al. (2005).

\section{Análises estatísticas dos dados}

A densidade de foraminíferos vivos, para análise comparativa, foi padronizada calculando-se a densidade de indivíduos em relação ao volume de $1 \mathrm{~cm}^{3}$ de sedimento. Desta forma, a densidade foi expressa como número de foraminíferos por $\mathrm{cm}^{3}$, conforme sugerido por Murray (2003). A riqueza foi definida como o número total de espécies identificadas em cada estação, a diversidade específica foi determinada pelo índice de Shannon-Wiener (Shannon, 1948):

$$
\mathrm{H}^{\prime}=-\sum p_{i} \ln p_{i}
$$

e a equitabilidade foi obtida de acordo com o índice de Pielou (Pielou, 1969):

$$
\mathrm{J}=\frac{H^{\prime}}{\ln S},
$$

onde: 1. $\mathrm{p}_{i}$ é a proporção de cada espécie na amostra; 2. $\mathrm{S}$ é o número de espécies identificadas em cada amostra; e 3. $\ln =\log _{\text {e }}$.

A influência dos parâmetros abióticos sobre as associações de foraminíferos foi analisada por meio de Análise de Componentes Principais (ACP), bem como por índices de correlação de Pearson (r), sendo o nível de significância ( $p$ level) analisado por meio do teste $t$ (Student).

A matriz biótica, para a elaboração da Análise de Componentes Principais, foi feita somente com espécies de foraminíferos que apresentaram abundância relativa superior ou igual a 5\%, em pelo menos uma estação. Espécies raras não foram consideradas, pois as mesmas apesar de não interferirem nos resultados, podem dificultar a interpretação da análise (Duleba e Debenay, 2003). A matriz abiótica, 
por sua vez, foi elaborada com as variáveis que apresentaram significativos índices de correlação em relação aos parâmetros bióticos, tais como: lama, areia, Cot, S, N, Ptotal, Eh, turbidez e oxigênio dissolvido.

Utilizou-se o programa computacional Minitab versão 15 (Minitab $^{\circledR}$ Inc.) para a preparação da ACP. Os dados utilizados para as análises estatísticas foram logaritimizados $(\ln x+1)$, com o intuito de normalizar as diferentes ordens de grandeza dos parâmetros estudados.

\section{RESULTADOS}

\section{Dados físico-químicos, granulométricos e geoquímicos}

Os posicionamentos das estações de amostragem e dados físico-químicos da coluna d'água encontram-se sumarizados na Tabela 1.

A região onde está posicionado o trecho difusor do emissário submarino da Baía do Araçá é ambiente raso, cujas profundidades variaram entre 3,5 e 15,5 m, com profundidade média de 10,5 $\mathrm{m}( \pm 3,6 \mathrm{~m})$.

Os valores de temperatura e salinidade oscilaram, respectivamente, entre 25,5 e $26,4^{\circ} \mathrm{C}$ e entre 33,8 e 34,6 . Já os valores de $\mathrm{pH}$ da coluna d'água variaram entre 7,90 e 8,22.

Em relação às concentrações de oxigênio dissolvido (OD), os valores encontrados foram de 5,06 a 6,95 $\mathrm{mg} \mathrm{L}^{-1}$. Os resultados obtidos nas estações Ar4, Ar7, Ar8, Ar9 e Ar10 apresentaram-se abaixo do limite para preservação da vida aquática, i.e. $6 \mathrm{mg} \mathrm{L}^{-1}$, estabelecido pela Resolução CONAMA 357/05, para águas salinas de Classe 1.

Os valores obtidos para a turbidez oscilaram de 0,77 (estação Ar6) a 12 UNT (estação Ar5).

Os resultados das análises granulométricas estão sumarizados na Tabela 2 e ilustrados na Figura 2.

A distribuição dos sedimentos coletados próximo ao emissário da Baía do Araçá ocorre de forma heterogênea, com predominância da fração areia (Figura 2). A maior concentração de sedimentos arenosos foi observada na estação $\operatorname{Ar} 1(89,33 \%)$, posicionada na saída do emissário submarino, região submetida ao maior volume do efluente disposto.

Sedimentos finos (silte + argila) ocorreram em maior concentração nas regiões leste (estações Ar9 e Ar10) e norte (estação Ar4) em relação à parte final do emissário submarino (Figura 2).

Excetuando-se a estação Ar10, grânulos, fração sedimentar $>2 \mathrm{~mm}$, foram observados nas demais estações em porcentagens que oscilaram entre 0,03 e 13,77\%. Em grande parte, a fração granulométrica identificada como grânulo é composta por fragmentos de conchas de moluscos.

De acordo com a classificação textural proposta por Shepard (1954), os sedimentos são denominados: 1. areia estações Ar1 e Ar6; 2. areia síltica - estações Ar2, Ar3, Ar5, Ar7 e Ar8; 3. silte arenoso - estações Ar4 e Ar9; e 4. silte argiloso - estação Ar10.

Em relação ao grau de seleção dos grãos, segundo a classificação proposta por Folk e Ward (1957), foram ob-

Tabela 1. Posicionamento geográfico das estações de amostragem e dados físico-químicos da coluna d'água. Obs.: * Valores de referências ambientais baseados na Resolução CONAMA 357/05, para águas salinas de Classe 1 . Em negrito, concentrações abaixo dos valores de referência ambiental.

\begin{tabular}{ccccccccc}
\hline Estações & Latitude & Longitude & $\begin{array}{c}\text { Profundidade } \\
(\mathbf{m})\end{array}$ & $\begin{array}{c}\text { Temperatura } \\
\left({ }^{\circ} \mathbf{C}\right)\end{array}$ & Salinidade & pH & $\begin{array}{c}\text { O. D. } \\
\left(\mathbf{m g} . \mathbf{L}^{-1}\right)\end{array}$ & $\begin{array}{c}\text { Turbidez } \\
(\text { UNT) }\end{array}$ \\
\hline \multicolumn{2}{c}{ Resolução CONAMA $357 / 05^{*}$} & & & $\geq 30$ & 6,5 a 8,5 & 6 & \\
\hline Ar1 & $-23,8193$ & $-45,4035$ & 6,5 & 26,2 & 34,1 & 8,19 & 6,58 & 0,87 \\
Ar2 & $-23,8199$ & $-45,4037$ & 10,5 & 26,1 & 34,1 & 8,16 & 6,36 & 1,6 \\
Ar3 & $-23,8194$ & $-45,403$ & 10,5 & 26,1 & 34,1 & 8,06 & 6,39 & 3,4 \\
Ar4 & $-23,8188$ & $-45,4028$ & 8,5 & 25,9 & 34,3 & 8,17 & $\mathbf{5 , 9 7}$ & 0,91 \\
Ar5 & $-23,8186$ & $-45,4041$ & 3,5 & 26,4 & 33,8 & 8,22 & 6,95 & 12 \\
Ar6 & $-23,8198$ & $-45,4043$ & 7,5 & 26,1 & 34,1 & 7,9 & 6,52 & 0,77 \\
Ar7 & $-23,8208$ & $-45,4050$ & 12,5 & 25,8 & 34,4 & 8,15 & $\mathbf{5 , 6 1}$ & 0,98 \\
Ar8 & $-23,8208$ & $-45,4036$ & 13,5 & 25,5 & 34,6 & 8,13 & $\mathbf{5 , 3 2}$ & 4,9 \\
Ar9 & $-23,8200$ & $-45,4024$ & 15,5 & 25,5 & 34,6 & 8,07 & $\mathbf{5 , 0 6}$ & 1,5 \\
Ar10 & $-23,8187$ & $-45,4025$ & 12,5 & 25,7 & 34,5 & 8,08 & $\mathbf{5 , 7 1}$ & 0,85 \\
\hline
\end{tabular}


Tabela 2. Resultado granulométrico obtido próximo ao emissário submarino da Baía do Araçá.

\begin{tabular}{|c|c|c|c|c|c|}
\hline Estações & $\begin{array}{c}\text { D. Padrão } \\
\delta\end{array}$ & $\begin{array}{c}\text { Grânulos } \\
\text { (\%) }\end{array}$ & $\begin{array}{c}\text { Areia } \\
(\%)\end{array}$ & $\begin{array}{c}\text { Silte } \\
(\%)\end{array}$ & $\begin{array}{c}\text { Argila } \\
(\%)\end{array}$ \\
\hline Ar1 & 1,92 & 2,27 & 89,33 & 5,18 & 3,22 \\
\hline Ar2 & 2,76 & 13,77 & 47,22 & 33,34 & 5,67 \\
\hline Ar3 & 2,28 & 0,37 & 64,00 & 29,36 & 6,27 \\
\hline Ar4 & 1,79 & 0,03 & 35,42 & 57,88 & 6,67 \\
\hline Ar5 & 1,70 & 0,06 & 57,03 & 35,55 & 7,36 \\
\hline Ar6 & 2,46 & 8,33 & 78,63 & 7,96 & 5,08 \\
\hline Ar7 & 3,05 & 4,04 & 63,31 & 21,92 & 10,73 \\
\hline Ar8 & 2,72 & 6,69 & 60,94 & 27,37 & 5,00 \\
\hline Ar9 & 2,98 & 6,52 & 31,62 & 51,46 & 10,40 \\
\hline Ar10 & 1,94 & 0,00 & 7,93 & 63,25 & 28,82 \\
\hline
\end{tabular}

servados sedimentos pobremente selecionados nas estações $\operatorname{Ar} 1, \operatorname{Ar} 4, \operatorname{Ar} 5$ e $\operatorname{Ar} 10$ (1,70 a 1,94 $\delta)$ e muito pobremente selecionados nas demais estações $(2,28$ a $3,05 \delta)$, o que permite inferir alternância na direção de fluxo, bem como intensidade das correntes.

Os resultados geoquímicos encontram-se mencionados na Tabela 3 .

Os valores de $\mathrm{pH}$ e de Eh dos sedimentos variaram entre 7,34 (Ar4) e 8,16 (Ar5) $(\bar{x}=7,78 \pm 0,29)$ e entre -211 (Ar5) e $-100 \mathrm{mV}$ (Ar6).

Os teores de $\mathrm{CaCO}_{3}$ foram de 7,7 a 29,9\% $(\bar{x}=18,7 \pm$ $6,7 \%$ ), o que confere a região estudada característica de ambiente litoclástico.

As concentrações de Cot oscilaram de 0,27 a 2,19\% $(\bar{x}=1,00 \pm 0,6 \%)$. As maiores porcentagens ocorreram na estação Ar4 (1,35\%), localizada na região norte da área de estudo, e estações $\operatorname{Ar} 9$ (1,73\%) e Ar10 (2,19\%), posi-

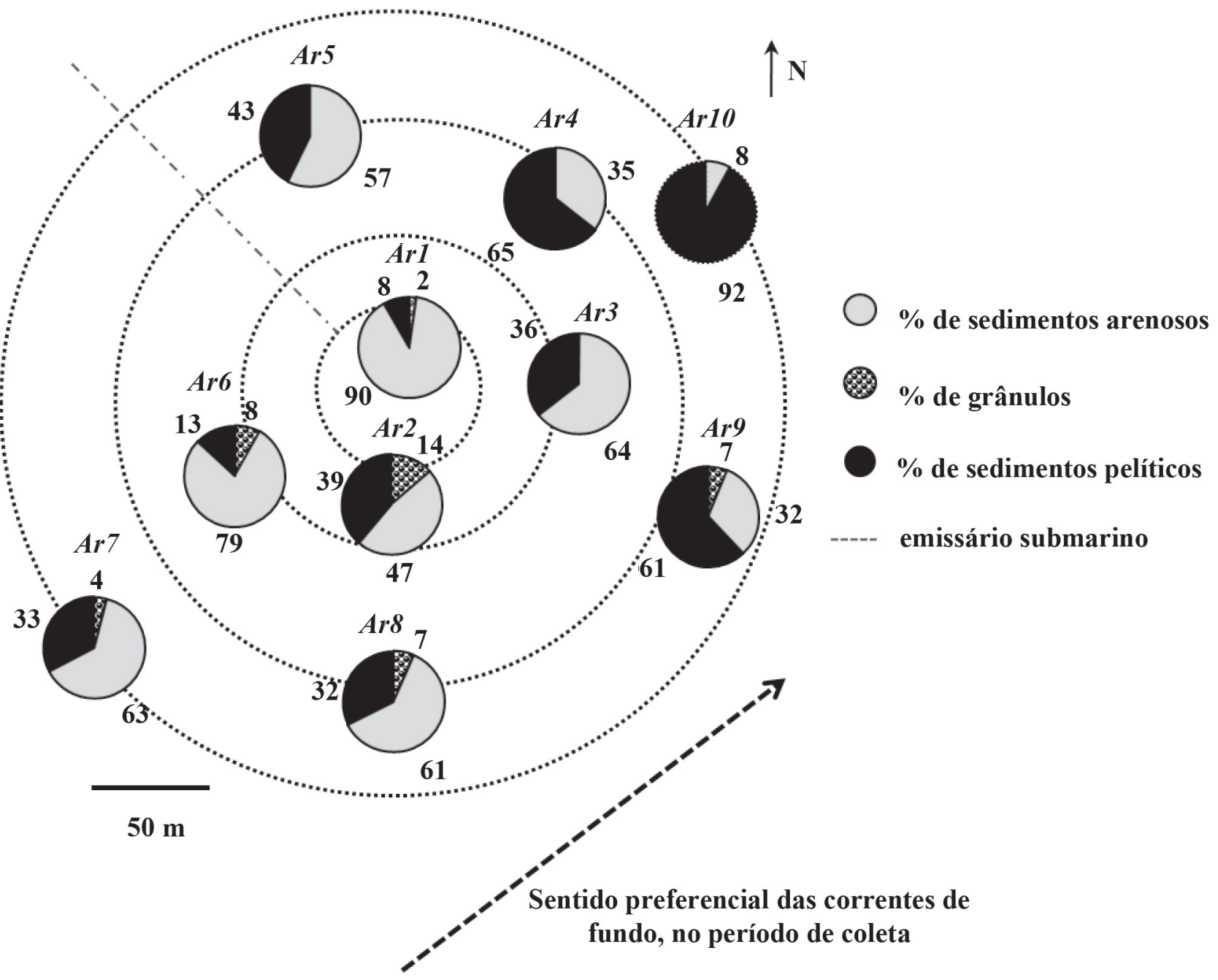

Figura 2. Distribuição granulométrica obtida próximo ao emissário submarino da Baía do Araçá. 
Tabela 3. Resultados das análises geoquímicas e razões elementares.

\begin{tabular}{cccccccccccc}
\hline Estações & $\mathbf{p H}$ & $\begin{array}{c}\text { EH } \\
(\mathbf{m V})\end{array}$ & $\begin{array}{c}\text { CaCO3 } \\
(\%)\end{array}$ & $\begin{array}{c}\text { Corg } \\
(\%)\end{array}$ & $\begin{array}{c}\mathbf{N} \\
(\%)\end{array}$ & $\begin{array}{c}\text { Ptotal } \\
(\%)\end{array}$ & $\begin{array}{c}\text { Porg } \\
(\%)\end{array}$ & $\begin{array}{c}\text { Pinorg } \\
(\%)\end{array}$ & $\begin{array}{c}\mathbf{S} \\
(\%)\end{array}$ & $\mathbf{C / N}$ & $\mathbf{C / S}$ \\
\hline Ar1 & 7,66 & -180 & 7,70 & 0,32 & 0,01 & 0,063 & 0,025 & 0,039 & 0,103 & 32,0 & 3,1 \\
Ar2 & 8,00 & -101 & 21,1 & 1,07 & 0,26 & 0,063 & 0,024 & 0,039 & 0,287 & 4,1 & 3,7 \\
Ar3 & 8,06 & -180 & 13,6 & 0,80 & 0,10 & 0,078 & 0,039 & 0,039 & 0,247 & 8,0 & 3,2 \\
Ar4 & 7,34 & -180 & 19,2 & 1,35 & 0,33 & 0,079 & 0,042 & 0,037 & 0,439 & 4,0 & 3,1 \\
Ar5 & 8,16 & -211 & 13,7 & 0,82 & 0,16 & 0,090 & 0,059 & 0,031 & 0,278 & 5,1 & 2,9 \\
Ar6 & 7,43 & -100 & 12,9 & 0,27 & 0,16 & 0,055 & 0,027 & 0,028 & 0,004 & 1,7 & 67,5 \\
Ar7 & 7,50 & -147 & 19,8 & 0,70 & 0,20 & 0,068 & 0,030 & 0,039 & 0,004 & 3,5 & 175 \\
Ar8 & 8,00 & -154 & 26,1 & 0,80 & 0,19 & 0,093 & 0,057 & 0,036 & 0,003 & 4,2 & 266,6 \\
Ar9 & 7,92 & -164 & 29,9 & 1,73 & 0,17 & 0,086 & 0,038 & 0,047 & 0,379 & 10,2 & 4,5 \\
Ar10 & 7,76 & -180 & 23,10 & 2,19 & 0,32 & 0,176 & 0,131 & 0,045 & 0,599 & 6,8 & 3,6 \\
\hline
\end{tabular}

cionadas na região leste. As menores concentrações ocorreram nas estações $\operatorname{Ar} 1(0,32 \%)$ e $\operatorname{Ar} 6(0,27 \%)$, localizadas na saída do emissário submarino e região sudoeste, respectivamente.

Os teores de $\mathrm{N}$ total variaram de 0,01 a $0,33 \%(\bar{x}=0,19$ $\pm 0,1 \%)$. As maiores porcentagens foram observadas nas estações $\operatorname{Ar} 4(0,33 \%)$ e $\operatorname{Ar} 10(0,32 \%)$, e a menor na estação $\operatorname{Arl}(0,01 \%)$.

Para os dados de $\mathrm{P}$, foram obtidos os seguintes valores: Ptotal 0,055 a $0,176 \%$; Porg 0,024 a $0,131 \%$ e Pinorg 0,028 a $0,047 \%$. A maior concentração de Ptotal e Porg ocorreu na estação Ar10, sendo observado na estação $\operatorname{Ar} 9$ o maior teor de Pinorg.

Os valores de S oscilaram entre 0,003 e $0,599 \%(\bar{x}=$ $0,23 \pm 0,20 \%$ ). As menores concentrações ocorreram quase na mesma proporção nas estações Ar6, Ar7 e Ar8, posicionadas nas regiões sudoeste e sul da área de estudo. A maior concentração ocorreu na estação Ar10.

Os valores das razões $\mathrm{C} / \mathrm{N}$ e C/S oscilaram, entre 4 e 32 e entre 2,9 e 266,6 respectivamente.

\section{Associações de foraminíferos - composição, distribuição e morfometria}

Devido à baixa densidade de foraminíferos bentônicos vivos, para a obtenção de 100 espécimes foram analisados volumes de sedimentos que oscilaram entre 10 e $40 \mathrm{~cm}^{3}$, sendo o volume de $20 \mathrm{~cm}^{3}$ utilizado em $80 \%$ das amostras analisadas (Apêndice 2).

Foram identificados 10 gêneros e 58 espécies, as quais estão distribuídas entre as Subordens Miliolina (10 espécies), Textulariina (7 espécies) e Rotaliina (41 espécies) (Apêndice 2).
As densidades de foraminíferos vivos por $\mathrm{cm}^{3}$ de sedimento variaram entre 3 e $25(\bar{x}=8 \pm 6)$. A maior densidade foi observada na estação Ar5, onde foram obtidos 25 foraminíferos por $\mathrm{cm}^{3}$ de sedimento. O contrário, por sua vez, ocorreu na estação Ar1, onde foram obtidos 3 foraminíferos por $\mathrm{cm}^{3}$ de sedimento.

Os valores de riqueza oscilaram entre 20 e 36 espécies. As maiores riquezas foram identificadas nas estações Ar6 (36 espécies) e Ar8 (34 espécies), e as menores nas estações $\operatorname{Ar} 3$ (20 espécies) e Ar10 (21 espécies).

Os valores de diversidade específica e equitatividade variaram entre 2,13 e 3,13 e entre 0,71 e 0,87 , respectivamente.

A espécie dominante em todas as estações analisadas é Ammonia tepida, cujas abundâncias relativas oscilaram entre 20 e $49 \%$ ( $\bar{x}=40,8 \pm 8 \%)$. As outras espécies com as maiores abundâncias relativas são, em ordem decrescente, Brizalina striatula (3 a 13\%; $\bar{x}=6,1 \pm 3,1 \%$ ), Buliminella elegantissima $(0,8$ a $9 \% ; \bar{x}=4,9 \pm 2,9 \%)$, Hopkinsina pacifica $(0,8$ a $8,6 \% ; \bar{x}=4,3 \pm 2 \%)$, Ammonia parkinsoniana (0 a $9,6 \% ; \bar{x}=3,8 \pm 2,7 \%)$, Pseudononion atlanticum ( 0 a $5 \% ; \bar{x}=3 \pm 1,5 \%)$, Rosalina floridensis $(0$ a $7 \% ; \bar{x}=$ $2,2 \pm 2,4 \%$ ), Cassidulina crassa $\mathrm{f}$. media (0 a $5 \% ; \bar{x}=2,1$ $\pm 1,6 \%$ ), Gaudryina exilis ( 0 a $7,6 \% ; \bar{x}=2 \pm 2,3 \%$ ) e Bolivina doniezi ( 0 a $5 \% ; \bar{x}=1,6 \pm 1,4 \%$ ).

No tocante a distribuição de espécies com preferências ecológicas semelhantes, observou-se predominância de espécies bioindicadoras de ambiente enriquecido organicamente (Apêndice 1.1) em detrimento a espécies bioindicadoras de ambiente óxico (Apêndice 1.2) (Figura 3). Menciona-se que Ammonia tepida não foi incluída em nenhum dos dois grupos; sua dominância poderia mascarar os resultados, motivo pelo qual se optou por não associá-la a um grupo em específico. 


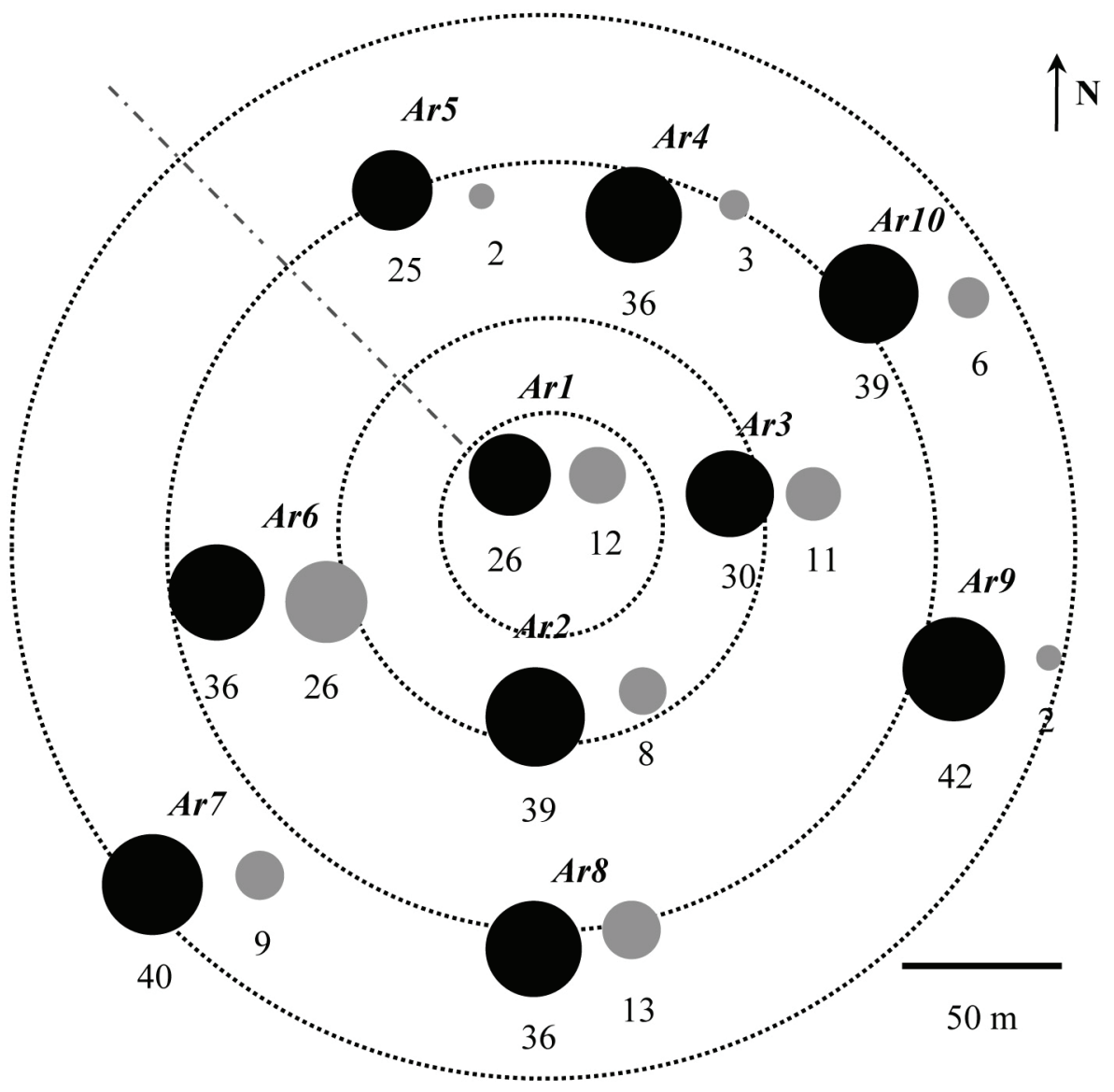

$\%$ de espécies bioindicadoras de ambiente óxico

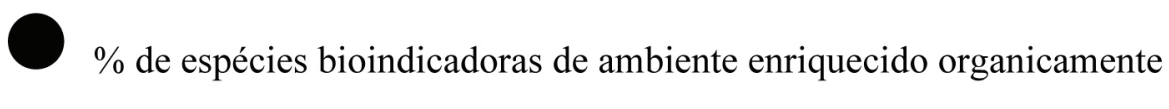

Figura 3. Abundâncias relativas de espécies bioindicadoras de ambiente enriquecido orga- - - emissário submarino nicamente e ambiente óxico, obtidas na Baía do Araçá.

A abundância de espécies bioindicadoras de ambiente rico em matéria orgânica perfaz 25 a $42 \%(\bar{x}=35 \pm 6 \%)$ das espécies de foraminíferos identificadas, e ocorre quase na mesma proporção em todas as estações analisadas, conforme pode ser observado na Figura 4.

Em contrapartida, espécies bioindicadoras de ambiente óxico possuem abundâncias relativas que variaram entre 2 e $26,4 \%$ ( $\bar{x}=9,6 \pm 7,4 \%)$. De modo geral, observou-se padrão de distribuição inversamente proporcional ao obtido para os resultados de Cot, S e P (todas as frações), i.e. com diminuição de porcentagens de sudoeste para norte-nordeste da área de estudo.
Em relação às análises morfométricas, foram identificadas três classes de tamanho (Figura 4).

Em todas as estações analisadas, carapaças médias são predominantes, com valores que oscilaram entre 53 e $69 \%$ $(\bar{x}=61 \pm 5 \%)$ (Figura 4$)$.

As porcentagens de carapaças pequenas variaram de 25 a $47 \%(\bar{x}=35 \pm 6 \%)$, sendo observada na estação Ar10 a maior porcentagem (Figura 4).

Excetuando-se a estação Ar10, carapaças grandes estiveram presentes em todas as demais estações, em porcentagens que oscilaram de 3 a $11 \%(\bar{x}=4 \pm 3 \%)$. A maior concentração de carapaças grandes foi identificada na es- 
Figura 4. Distribuição das classes de tamanho de foraminíferos obtidas próximo ao emissário submarino da Baía do Araçá.

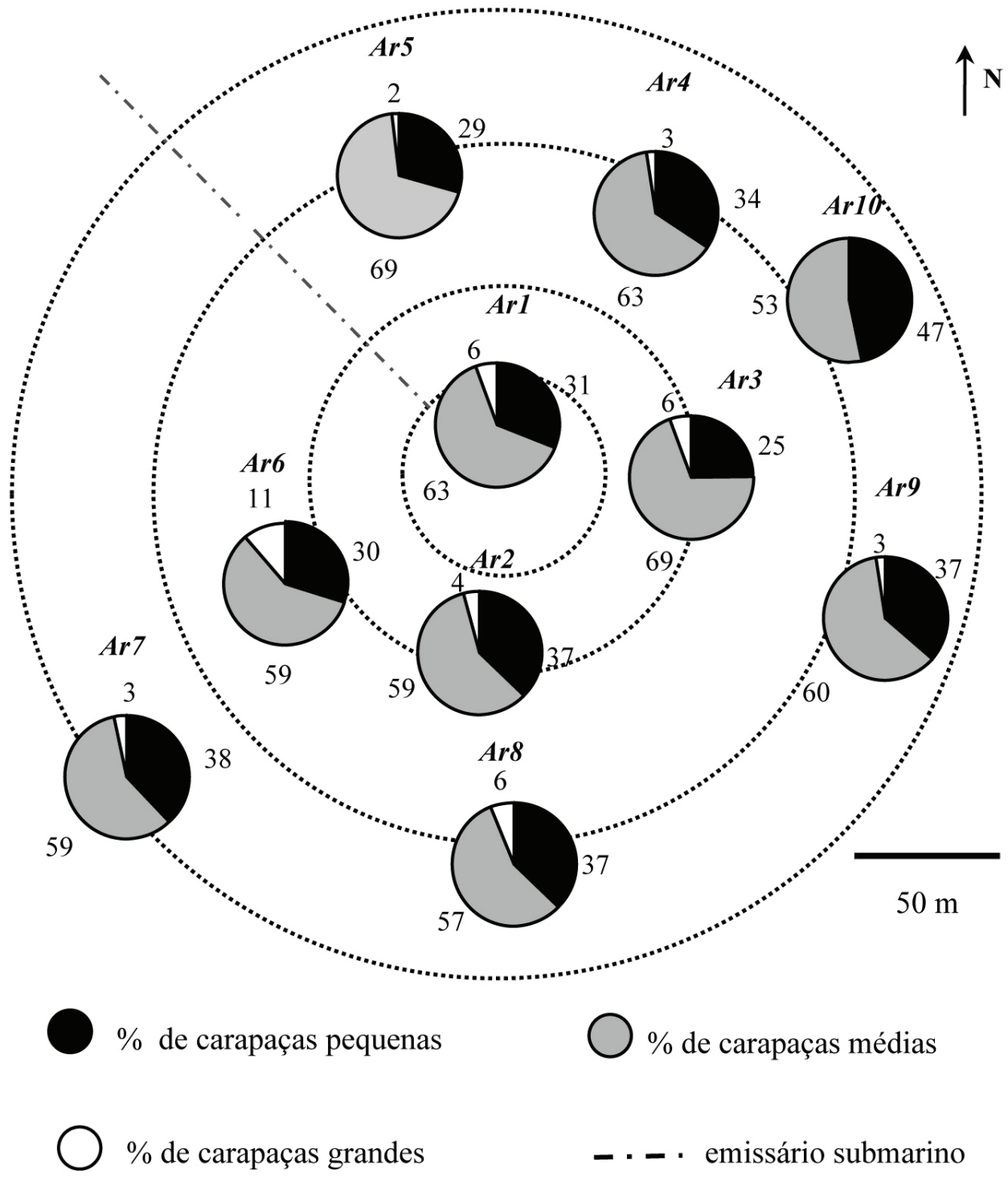

tação Ar6, posicionada na região sudoeste, em relação à saída do emissário submarino.

\section{Dados estatísticos}

Os coeficientes de correlação, apresentados na Tabela 4 , indicam que as associações de foraminíferos são, em geral, negativamente influenciadas pelos parâmetros abióticos estudados. As riquezas de espécies possuem significante relação inversa em relação a carbono orgânico total, Eh, enxofre e fósforo inorgânico. Diversidade específica é negativamente influenciada por Eh, e em menor escala por enxofre e fósforo inorgânico. A equitatividade, por sua vez, possui relação inversa em relação ao Eh. O parâmetro densidade possui significativa correlação positiva com o parâmetro turbidez.

A composição das associações, i.e. espécies bioindicadoras de ambiente enriquecido por matéria orgânica e ambiente óxico, bem como o tamanho das carapaças de foraminíferos, também são significantemente influenciados pelos parâmetros abióticos, conforme observado na Tabela 4.

Conforme observado no diagrama de ordenação da Análise de Componentes Principais (Figura 5), 57\% dos 
Tabela 4. Índices de Correlação de Pearson obtidos entre parâmetros bióticos e abióticos. Legenda: E.B.A.R.M.O. = espécies bioindicadoras de ambiente enriquecido por matéria orgânica e E.B.A.O. = espécies bioindicadoras de ambiente óxico.

\begin{tabular}{|c|c|c|c|c|c|c|c|c|c|}
\hline & $\begin{array}{l}\frac{0}{0} \\
\frac{\pi}{0} \\
\frac{0}{\omega} \\
\frac{0}{0} \\
\stackrel{0}{0}\end{array}$ & $\begin{array}{l}\text { N } \\
\frac{N}{2} \\
\frac{\sigma}{\alpha}\end{array}$ & İ & $\supset$ & $\begin{array}{l}0 \\
\Sigma \\
\Sigma \\
\dot{\Sigma} \\
\dot{<} \\
\dot{\infty} \\
\dot{\omega}\end{array}$ & $\begin{array}{l}0 \\
\dot{\varangle} \\
\dot{0} \\
\text { ம }\end{array}$ & 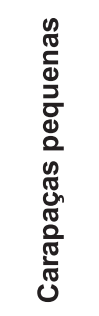 & 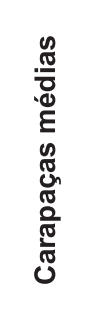 & 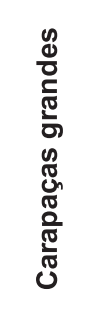 \\
\hline Profundidade & $-0,38$ & $-0,06$ & 0,07 & 0,17 & 0,83 & 0,12 & 0,57 & $-0,62$ & $-0,12$ \\
\hline O. D. & 0,07 & $-0,03$ & $-0,09$ & $-0,10$ & $-0,75$ & 0,19 & $-0,64$ & 0,59 & 0,24 \\
\hline Turbidez & 0,80 & 0,04 & $-0,28$ & $-0,49$ & $-0,54$ & $-0,31$ & $-0,39$ & 0,53 & 0,00 \\
\hline $\mathrm{pH}$ (sedimento) & 0,51 & $-0,19$ & $-0,38$ & $-0,45$ & $-0,29$ & $-0,26$ & $-0,17$ & 0,29 & $-0,12$ \\
\hline EH (sedimento) & 0,17 & $-0,61$ & $-0,70$ & $-0,60$ & $-0,50$ & $-0,58$ & $-0,11$ & 0,41 & $-0,47$ \\
\hline Lama & 0,31 & $-0,52$ & $-0,36$ & $-0,06$ & 0,46 & $-0,69$ & 0,50 & $-0,20$ & $-0,76$ \\
\hline Areia & 0,04 & 0,48 & 0,12 & $-0,29$ & $-0,46$ & 0,43 & $-0,72$ & 0,55 & 0,88 \\
\hline $\mathrm{CaCO} 3$ & 0,28 & 0,00 & 0,08 & 0,15 & 0,81 & $-0,38$ & 0,67 & $-0,54$ & $-0,40$ \\
\hline СOT & 0,12 & $-0,57$ & $-0,33$ & 0,00 & 0,51 & $-0,67$ & 0,64 & $-0,36$ & $-0,81$ \\
\hline $\mathrm{N}$ & 0,15 & $-0,11$ & 0,09 & 0,31 & 0,64 & $-0,34$ & 0,64 & $-0,50$ & $-0,57$ \\
\hline Ptotal & 0,04 & $-0,41$ & $-0,14$ & 0,18 & 0,18 & $-0,30$ & 0,61 & $-0,47$ & $-0,86$ \\
\hline Porg & 0,10 & $-0,33$ & $-0,07$ & 0,23 & 0,11 & $-0,25$ & 0,56 & $-0,45$ & $-0,82$ \\
\hline Pinorg & $-0,36$ & $-0,62$ & $-0,45$ & $-0,19$ & 0,45 & $-0,39$ & 0,56 & $-0,35$ & $-0,54$ \\
\hline$S$ & 0,05 & $-0,75$ & $-0,48$ & $-0,07$ & 0,13 & $-0,69$ & 0,32 & $-0,04$ & $-0,75$ \\
\hline
\end{tabular}

$p<0,01$

$p<0,05$

dados de variabilidade total pode ser explicado pelos dois principais componentes, sendo que o primeiro corresponde a $36 \%$, e o segundo corresponde a $20 \%$.

No primeiro componente verifica-se a presença de grande maioria das variáveis abióticas, tais como lama, oxigênio dissolvido (O.D.), areia, Cot, N, Ptotal, S, e as espécies B. striatula, B. marginata, B. elegantissima, $C$. crassa, H. pacifica, P. atlanticum. No segundo gradiente, por sua vez, observa-se a presença dos parâmetros turbidez, $\mathrm{pH}$, Eh, e as espécies $A$. parkinsoniana, A. tepida, $D$. doniezi, G. exilis e R. floridensis.
De acordo com o diagrama de dispersão (Figura 6), dois grupos de estações foram identificados. O Grupo I (Ar2, Ar4, Ar9 e Ar10), caracterizado por maiores concentrações de lama, nutrientes, Cot e S e o Grupo II (Ar3, Ar6, Ar7 e Ar8), caracterizado por sedimentos mais arenosos, com baixas concentrações de matéria orgânica. As estações Ar1 e Ar5, posicionadas na extremidade dos eixos horizontal (primeiro componente) e vertical (segundo componente), respectivamente, não foram associadas a nenhum grupo.

Algumas das espécies acima mencionadas encontram-se ilustradas na Figura 7. 


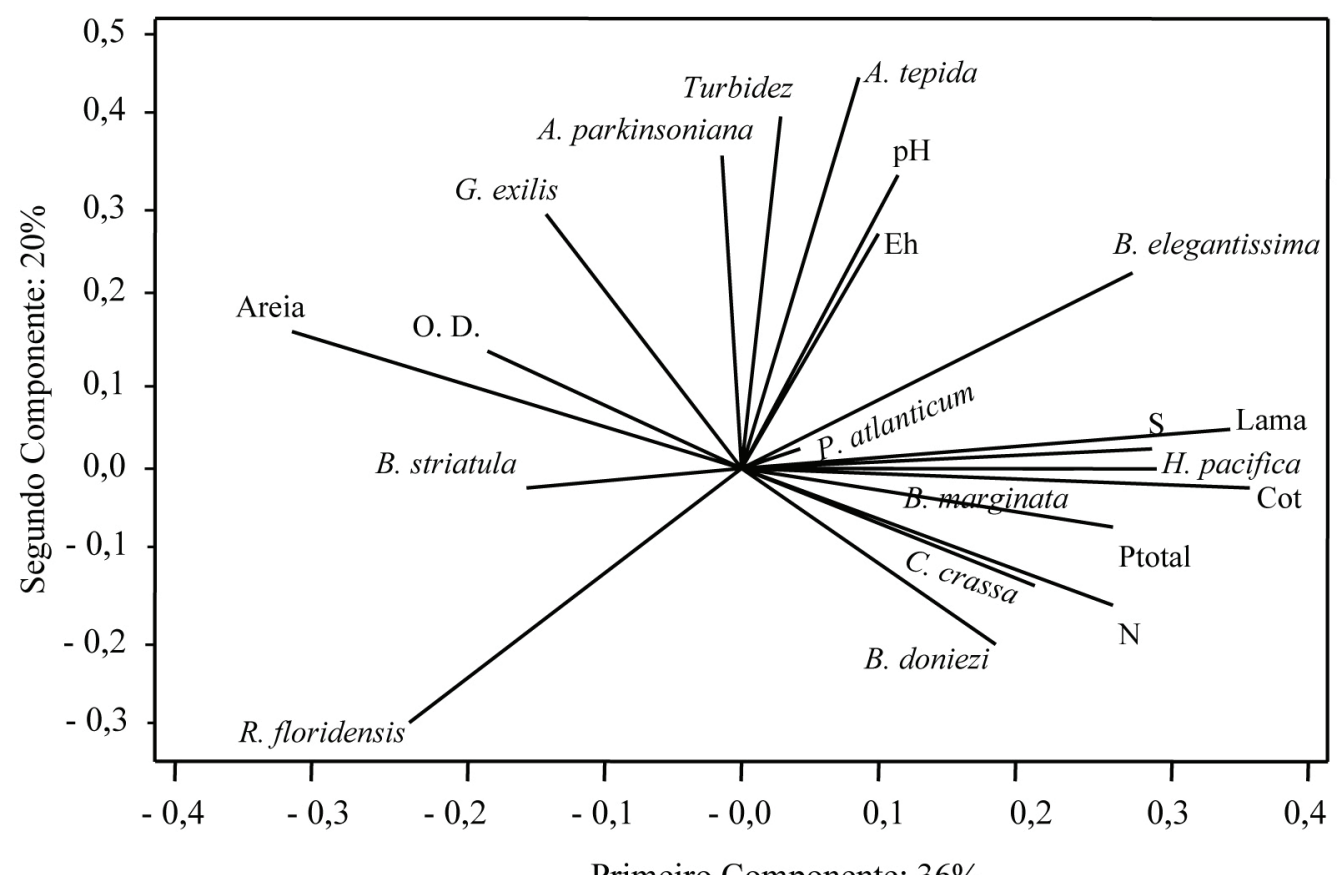

Primeiro Componente: $36 \%$

Figura 5. Representação gráfica da Análise de Componentes Principais, baseada em parâmetros bióticos e abióticos.

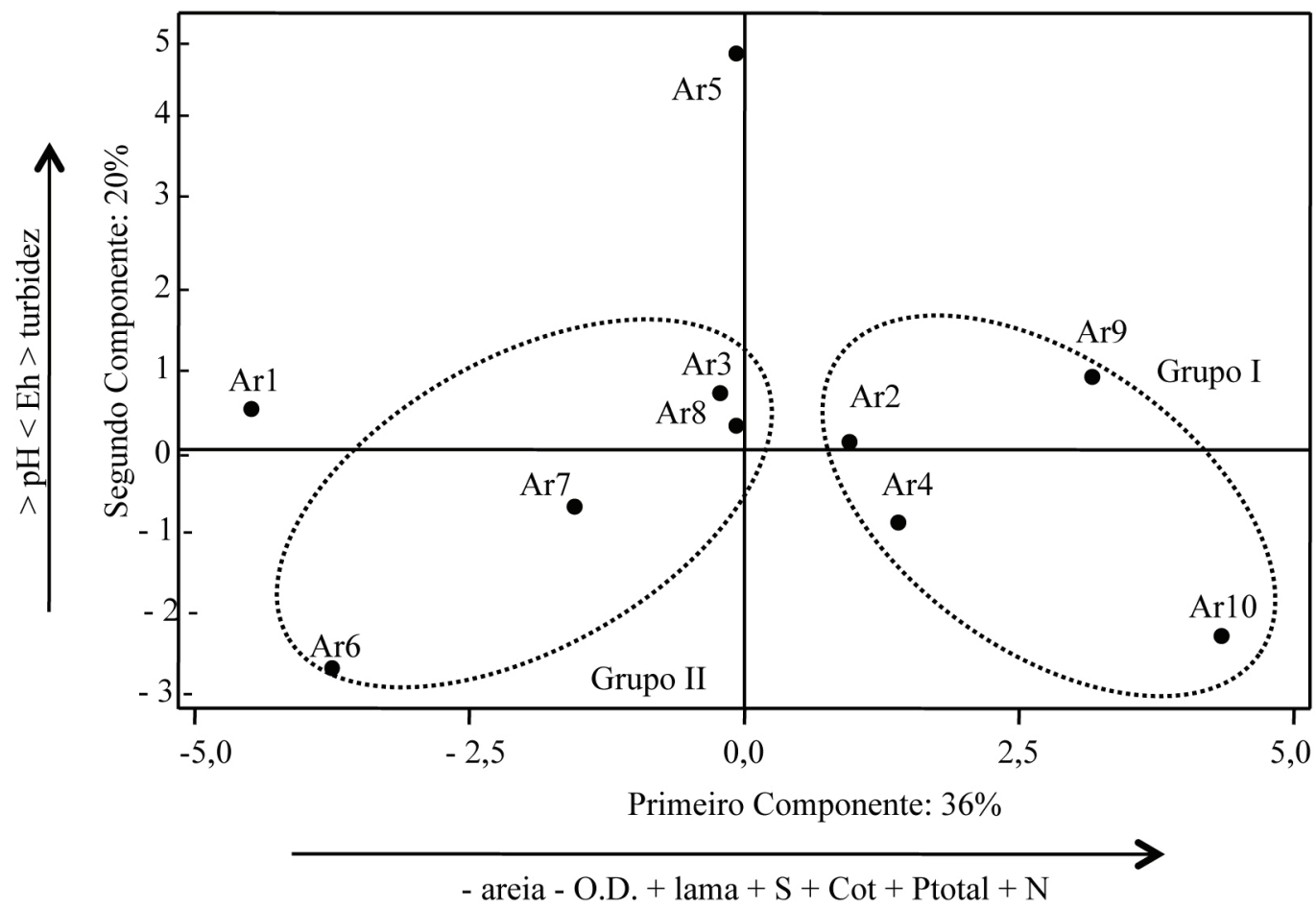

Figura 6. Representação gráfica da Análise de Componentes Principais, baseada na dispersão das estações amostradas. 

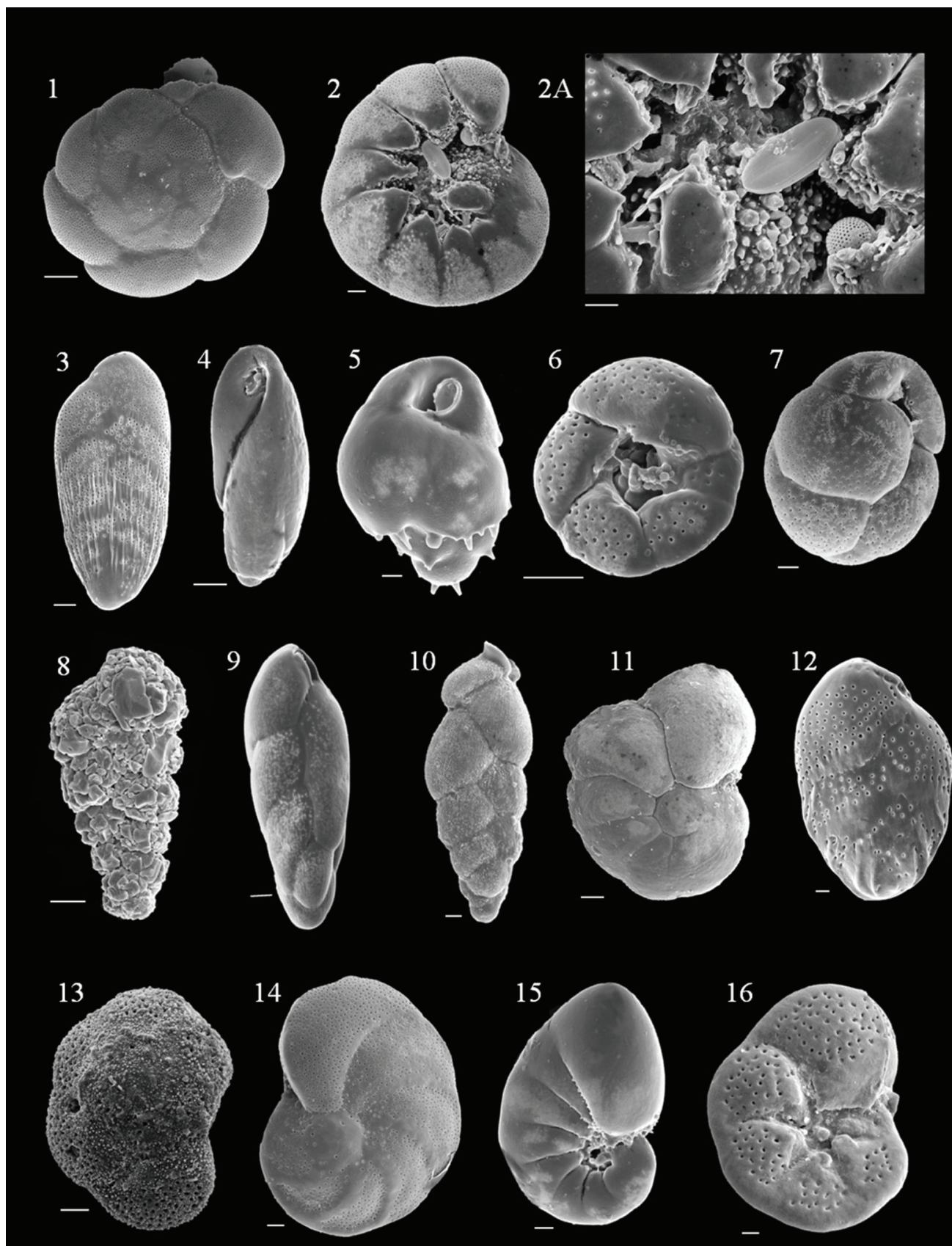

Figura 7. Micrografias das principais espécies de foraminíferos bentônicos vivos obtidos próximo ao emissário submarino da Baía do Araçá: 1. Ammonia tepida, lado ventral (30 $\mu \mathrm{m})$, 2. Ammonia tepida, lado umbilical $(20 \mu \mathrm{m}),(2 \mathrm{~A})$ lado umbilical Ammonia tepida, onde são observadas frústulas de diatomáceas $(10 \mu \mathrm{m})$, 3. Brizalina striatula $(20 \mu \mathrm{m})$, 4. Buliminela elegantissima $(30 \mu \mathrm{m}), 5$. Bulimina marginata $(10 \mu \mathrm{m}), 6$. Neocornobina terquemi, lado umbilical $(30 \mu \mathrm{m})$, 7. Cassidulina crassa f. media $(20 \mu \mathrm{m}), 8$. Gaudryina exilis $(30 \mu \mathrm{m}), 9$. Fursenkoina pontoni $(20 \mu \mathrm{m}), 10$. Hopkinsina pacifica $(10 \mu \mathrm{m}), 11$. Lobatula lobatula $(30 \mu \mathrm{m}), 12$. Bolivina ordinaria $(10 \mu \mathrm{m}), 13$. Pararotalia cananeiaensis, lado ventral $(20 \mu \mathrm{m}), 14$. Hanzawaia boueana, lado ventral $(20 \mu \mathrm{m}), 15$. Pseudononion atlanticum, lado umbilical $(20 \mu \mathrm{m}), 16$. Rosalina floridensis, lado umbilical $(20 \mu \mathrm{m})$. 


\section{DISCUSSÃO}

\section{Parâmetros físico-químicos}

Não foram observadas estratificações termohalinas, o que se deve a pouca profundidade da área de estudo. Os valores de $\mathrm{pH}$, entre 7,5 e 8,4, são característicos de ambiente marinho (Soares-Gomes e Figueiredo, 2002).

Das dez estações analisadas, cinco estações (estações Ar4, Ar7 a Ar10) apresentaram níveis de oxigênio dissolvido abaixo do limite de proteção à vida aquática estabelecido pela Resolução CONAMA 357/2005, para águas salinas de Classe 1 (i.e. inferiores a $6 \mathrm{mg} \mathrm{L}^{-1}$ ). Os baixos valores obtidos, aparentemente, podem indicar a presença da pluma originada pelo efluente, não sendo, entretanto, observado um sentido preferencial de dispersão.

O efluente disposto pelo emissário submarino da Baía do Araçá, antes de ser liberado, recebe somente pré-condicionamento. Devido ao fato de o esgoto ser predominantemente doméstico, há a liberação para o ecossistema aquático de significativa quantidade de matéria orgânica dissolvida e particulada. A decomposição da matéria orgânica lábil por microorganismos tende a acelerar o consumo de oxigênio do meio, e por consequência, acarretar a diminuição de oxigenação das águas de fundo (Connel e Miller, 1984; Esteves, 1998).

Os valores de turbidez, a qual pode estar relacionada à matéria orgânica particulada contida no efluente, são considerados significativos. Os maiores valores, excetuando-se a estação Ar5, foram observados nas estações Ar2, Ar8, posicionadas na região sul em relação à parte final do emissário submarino, e estações $\operatorname{Ar} 3$ e $\operatorname{Ar} 9$, região sudeste, indicando possível sentido de dispersão da pluma para estas regiões. $\mathrm{O}$ valor de turbidez obtido para a estação Ar5 (12 UNT), por sua vez, pode estar relacionado ao revolvimento dos sedimentos de fundo pelas correntes e/ou pela embarcação, uma vez que esta estação está posicionada a uma profundidade de $3,5 \mathrm{~m}$, bem como pode ser indicativo de processo de eutrofização, o qual será posteriormente discutido.

\section{Parâmetros granulométricos e geoquímicos}

Os resultados das análises granulométricas indicam a predominância de sedimentos arenosos, o que corrobora os resultados obtidos em estudo anterior (Gubitoso et al., 2008). A heterogeneidade granulométrica, a qual se reflete no baixo grau de seleção encontrado, pode ser associado às constantes alternâncias de energia e direção das correntes de fundo que ocorrem na região, bem como a geometria e a topografia do canal (Furtado, 1995; Furtado et al., 2008). A quebra de energia das correntes de fundo, que propicia a deposição de sedimentos pelíticos (silte e argila), é marcada pela constante presença de minerais micáceos.

Por meio da distribuição granulométrica, apresentada na Figura 2, percebe-se predominância de sedimentos pelíticos a nordeste do trecho difusor do emissário submarino. Segundo Silva, Miranda e Castro (2001), no outono, período em que foi realizada a coleta das amostras (Abril de 2006), a circulação é unidirecional em sentido nordeste, com correntes de superfície de sudoeste para nordeste.

Os parâmetros geoquímicos analisados possuem distribuição diretamente relacionada à composição textural dos sedimentos. Tal fato ocorre devido à maior capacidade de adsorção dos grãos; as concentrações aumentam com a diminuição do tamanho dos grãos (Bordovskiy, 1965). Diante disto, elevadas concentrações de Cot, N, P e S não foram identificadas na estação Arl, localizada na saída do emissário submarino, mas sim em estações com elevados teores de silte e argila.

O enriquecimento orgânico que há na região é caracterizado principalmente por nitrogênio, fósforo e enxofre. Os teores de carbono orgânico são considerados moderados; somente a estação Ar10, localizada a nordeste da área de estudo, apresentou teores similares aos obtidos em regiões sob processos de eutrofização (entre 2 e 4\%) (Diz, Francés, Rosón, 2006).

Nitrogênio e fósforo são nutrientes que contribuem para o aumento da produção primária. Quando em excesso podem iniciar processos de eutrofização e, por conseguinte, alterações ambientais, tais como turbidez, gerada pelo aumento de biomassa microalgal, e depleção nos níveis de oxigenação (Esteves, 1998). O aporte destes dois nutrientes para o ambiente marinho pode ocorrer de forma natural e/ou antrópica. Dentre as fontes antrópicas, a principal delas é a disposição oceânica de esgotos domésticos, rica em compostos nitrogenados (Aston e Hewit, 1977; Faganelli et al., 1988) e fosfatados (Lassen, Tjell, Hanse, 1984; Faganelli et al., 1988; Ozório e Oliveira, 2001).

Os teores de fósforo total, em $60 \%$ das estações analisadas (i.e. estações $\operatorname{Ar} 3$ a $\operatorname{Ar} 5$ e $\operatorname{Ar} 8$ a Ar10), são característicos de regiões sob influência de atividades antropogênicas $(>0,07 \%)$ (Baturin, 2003). A influência antrópica para o aporte de fósforo é corroborada pela elevada porcentagem da fração inorgânica, a qual, segundo Ozório e Oliveira (2001), está associada a fertilizantes e detergentes polifosfatados e ortofosfatados, e a fosfatos inorgânicos condensados de esgotamentos sanitários não tratados.

Atualmente, a fração inorgânica do fósforo encontra-se adsorvida nos sedimentos devido às características redutoras dos mesmos. Contudo, em condições de maior oxigenação, tal fração poderá ser disponibilizada para a coluna d'água, enriquecendo-a de nutriente, e por consequência iniciar processo de eutrofização. 
Assim como para nitrogênio e fósforo, as concentrações de enxofre obtidas são indicativas de atividades antrópicas (i.e. $>0,13 \%$ ) (Turekian e Wedepohl, 1961). O esgoto liberado além de ser enriquecido por matéria orgânica, a qual possui como um de seus componentes o enxofre, contém detergentes que possuem em sua formulação compostos oriundos de enxofre, como por exemplo, dodecil sulfonato de sódio, linear alquilbenzeno sulfonato de sódio e sulfato de magnésio (Cabrera, 2005).

$\mathrm{Na}$ tentativa de identificar a proveniência da matéria orgânica e consequentemente de seus componentes, optou-se pelo estudo de razões $\mathrm{C} / \mathrm{N}$. Apesar de a área de estudo estar posicionada próximo ao continente, infere-se que a principal fonte de matéria orgânica para a região é o esgoto disposto pelo emissário submarino. Tal inferência deve-se ao fato de que a estação Ar1, localizada na saída do emissário submarino, é a única estação que apresentou matéria orgânica de origem continental $(\mathrm{C} / \mathrm{N}>12)$. Mistura de origens, marinha e continental, razões $\mathrm{C} / \mathrm{N}$ entre 6 e 12, que também refletem o efluente disposto, ocorreram nas estações posicionadas no sentido preferencial da dispersão do efluente e do material particulado a ele associado (i.e. estações Ar3, Ar9 e Ar10). As estações Ar6, Ar7 e $A r 8$, posicionadas na região sudoeste, sob maior influência marinha, apresentaram valores de razão $\mathrm{C} / \mathrm{N}$ característicos de contribuição fito e zooplanctônica $(\mathrm{C} / \mathrm{N}<6)$.

$\mathrm{Na}$ ausência de análises quantitativas, para analisar a concentração de oxigênio dissolvido na interface água-sedimento, métodos quantitativos indiretos e qualitativos têm sido empregados, dentre os quais se menciona a análise do Eh e o estudo das razões C/S (Burone et al., 2006; Mojtahid, Jorissen, Pearson, 2008).

A utilização de razões $\mathrm{C} / \mathrm{S}$, como proxie qualitativo para diferenciar sedimentos depositados em condições óxicas de sedimentos depositados em eventos de anoxia ou de semianoxia, é baseada em processos de redução de sulfato por bactérias sulfato redutoras (Stein, 1991; Borrego et al., 1998). As razões $\mathrm{C} / \mathrm{S}$ refletem a redução do sulfato durante a decomposição da matéria orgânica, tornando possível inferir as condições do potencial redox do ambiente deposicional (Borrego et al., 1998). Valores de razões $\mathrm{C} / \mathrm{S}$, em média, inferiores a $2,8 \pm 0,8$ indicam sedimentos depositados sob condições redutoras (Lyons e Berner, 1992; Borrego et al., 1998). Mediante ao exposto, sedimentos com evidências de hipoxia, cuja matéria orgânica aparentemente está sendo degradada sob anaerobiose, foram observadas nas estações Ar1, Ar3, Ar4, Ar5 e Ar10.

Os valores de Eh, de forma geral, corroboram as informações inferidas pelas razões $\mathrm{C} / \mathrm{S}$, uma vez que os valores medidos evidenciam aumento de consumo de oxigênio na interface água-sedimento para degradação de elevada quantidade de matéria orgânica. Segundo Sutherland et al.
(2007), valores de Eh entre -50 e - $150 \mathrm{mV}$, similares aos encontrados nas estações Ar2, Ar6 a Ar8 são comumente encontrados em ambientes com sinais de hipoxia $\left(<2 \mathrm{mg} \mathrm{L}^{-1}\right.$; in Tyson e Pearson, 1991). Já os valores obtidos para as demais estações $(<-150 \mathrm{mV})$, segundo os mesmos autores, são encontrados em ambientes anóxicos. Dentro da faixa de valores de Eh obtida para o presente estudo, entre -211 a $-100 \mathrm{mV}$, já há redução de nitrogênio para nitrogênio amoniacal e de enxofre para sulfeto (Mitsch e Gosselink, 1986 in Esteves, 1998).

\section{Associações de foraminíferos bentônicos: composição, distribuição e morfometria}

Apesar de significativo o número de estudos sobre poluentes orgânicos e inorgânicos onde foraminíferos bentônicos são utilizados como bioindicadores (q.v. Alve, 1995 e Nigan, Saraswat, Panchang, 2006 para revisão), há grande complexidade no entendimento de quais os fatores abióticos que podem influenciar as associações de foraminíferos, principalmente quando se trata de ambientes costeiros e estuarinos. Em tais regiões, diferentes tipos de poluentes podem ser lançados ao mesmo tempo e os foraminíferos bentônicos podem responder de formas distintas a presença de vários tipos de poluentes, sejam estes orgânicos ou inorgânicos. Dentre elas cita-se a diminuição de densidade e riqueza, aumento de espécies tolerantes, podendo em alguns casos ocorrer ausência de espécimes (Alve, 1995).

No presente estudo, por meio de Análise de Componentes Principais e de índices de correlação de Pearson, observou-se que as principais variáveis abióticas que influenciam a distribuição e a composição das associações de foraminíferos são os teores de carbono orgânico total, de enxofre, de fósforo inorgânico e o potencial de oxirredução dos sedimentos (Eh).

Considera-se significativa a diferença de densidade de foraminíferos bentônicos vivos, a qual é mais acentuada na estação Ar5. A estação Ar5, com 25 foraminíferos por $\mathrm{cm}^{3}$, comparativamente às demais estações, apresentou em média 4 vezes mais espécimes por $\mathrm{cm}^{3}$. A elevada densidade de foraminíferos pode estar associada ao processo de eutrofização que, aparentemente, ocorreu nesta estação, e que é inferido pelas concentrações de clorofila $a\left(18,86 \mu \mathrm{g} \mathrm{L}^{-1}\right.$; CETESB, 2007) e feofitina $\left(5,15 \mu \mathrm{g} \mathrm{L} \mathrm{L}^{-1}\right.$; CETESB, 2007). A clorofila $a$, por ser a mais comum das clorofilas representa aproximadamente 1 a $2 \%$ do peso seco de material orgânico em todas as algas planctônicas, fato que a faz indicadora de biomassa algal (Wetzel e Likens, 1991), sendo, portanto, considerada como principal variável indicadora do estado trófico em ambientes aquáticos. A feofitina, por sua vez, é o produto da degradação da clorofila $a$, motivo pelo qual se infere que eleva- 
das concentrações de feoftina são indicativas de processo de eutrofização (Wetzel e Likens, 1991).

A disposição oceânica de esgotos domésticos pode ter efeito negativo, positivo ou nulo sobre as associações de foraminíferos (Alve, 1995). Um efeito positivo indireto é o aumento da biomassa microalgal (produtores primários), devido ao aporte contínuo de nutrientes (Ward, Pond, Murray, 2003). O aumento da biomassa microalgal, apesar de não ter sido quantificado, foi evidenciado pela elevada concentração de frústulas de diatomáceas observadas nos sedimentos da estação $\operatorname{Ar} 5$.

$\mathrm{O}$ aumento de produtores primários é considerado suprimento alimentar para espécies de foraminíferos herbívoros (Ward, Pond, Murray, 2003; Armynot du Chatêlet, Debenay, Soulard, 2004), como por exemplo, para o gênero Ammonia. Em estudo realizado na Baía de Ubatuba (SP), Burone et al. (2007) observaram dominância da espécie Ammonia tepida em estações com elevadas concentrações de clorofila $a$. Assim como o observado pelos autores, no presente estudo, na estação Ar5, ocorreu a maior abundância de Ammonia spp. (59,3\%). Do total de espécimes identificados $7,5 \%$ são formas juvenis, o que, aparentemente, indica aumento na taxa de reprodução devido à abundância de alimento e ausência de competição entre as espécies.

As riquezas apresentam distribuição inversamente proporcional ao padrão de concentração observado para aos parâmetros enxofre $(\mathrm{r}=-0,75 ; p<0,01)$, fósforo inorgânico $(\mathrm{r}=-0,62 ; p<0,01)$ e carbono orgânico $(\mathrm{r}=-0,57$; $p<0,01)$. Em relação ao parâmetro Eh, observou-se correlação negativa com os parâmetros bióticos riqueza ( $\mathrm{r}$ $=-0,61 ; p<0,01)$, diversidade específica $(\mathrm{r}=-0,70 ; p<$ $0,01)$ e equitatividade $(\mathrm{r}=-0,60 ; p<0,01)$. Os maiores valores de riqueza ocorreram nas estações Ar6 (36 espécies) e Ar8 (34 espécies), posicionadas na parte mais externa da malha de amostragem, em sentido oposto ao da área sob maior influência da disposição oceânica.

$\mathrm{Na}$ maioria dos ecossistemas bentônicos, a oxigenação e a disponibilidade de alimento são consideradas fatores limitantes, sendo responsáveis pela densidade da microfauna bentônica, bem como pela sua composição (Jorissen et al., 1992).

Por meio da associação de espécies com preferências ecológicas similares, observou-se predominância de espécies bioindicadoras de ambiente com baixos níveis de oxigenação e enriquecido organicamente (Anexo 1.1) em detrimento a espécies bioindicadoras de ambiente óxico e pobre em matéria orgânica (Anexo 1.2). Menciona-se que Ammonia tepida não foi incluída em nenhuma das duas associações; sua dominância poderia mascarar os resultados, motivo pelo qual se optou por não associá-la a uma associação em específico.
Espécies bioindicadoras de ambiente enriquecido organicamente são, em grande maioria, organismos detritívoros, comumentemente associados a elevado aporte de matéria orgânica, baixo grau de oxigenação na interface água-sedimento e fraco hidrodinamismo. Esta associação está positivamente relacionada à profundidade $(\mathrm{r}=0,83$; $\mathrm{p}<0,01)$, aos teores de nitrogênio $(\mathrm{r}=0,64, p<0,01)$ e em menor proporção aos teores de carbono orgânico $(\mathrm{r}=$ $0,51 ; p<0,01)$ e a fósforo inorgânico $(\mathrm{r}=0,45 ; p<0,01)$.

Espécies bioindicadoras de ambiente bem oxigenado, por sua vez, são epifaunais, menos tolerantes a estresse ambiental (Jorissen et al., 1992), em sua grande maioria herbívoras, e que têm sido observadas em abundância em ambientes com forte hidrodinamismo e com baixas concentrações de matéria orgânica.

As principais espécies que o compõem são Cibicides spp., Rosalina floridensis, Neocornobina terquemi, Quinqueloculina spp., Lobatula lobatula, Gavelinopsis praegeri. Observou-se que espécies bioindicadoras de ambiente bem oxigenado estão inversamente distribuídas em relação aos teores de enxofre $(\mathrm{r}=-0,69 ; p<0,01)$ e de carbono orgânico $(\mathrm{r}=-0,67 ; p<0,01)$ e aos valores de $\mathrm{Eh}(\mathrm{r}=$ - 0,58; $p<0,01)$. As maiores abundâncias, de forma geral, foram observadas em estações posicionadas na região sudoeste em relação ao trecho difusor do emissário submarino, a qual está sob maior influência de águas marinhas provenientes da região adjacente à área de estudo, sem influência do esgoto disposto pelo emissário submarino.

Por meio da Análise de Componentes Principais, excetuando as estações Ar1 e Ar5, observou-se, ao integrar dados abióticos e bióticos, a formação de dois grupos de estações, com características ambientais diferentes. O Grupo I, composto pelas estações Ar2, Ar4, Ar9 e Ar10, é caracterizado como ambiente com acúmulo de nutrientes, enxofre e carbono orgânico total. Neste grupo, as espécies de foraminíferos são predominantemente bioindicadoras de estresse ambiental (e.g. Buliminella elegantissima, Hopkinsina pacifica, Bulimina marginata, Cassidulina crassa, Pseudononion atlanticum). O Grupo II, formado pelas estações Ar3, Ar6, Ar7 e Ar8, por sua vez, estão posicionadas em ambiente com ausência e/ou fraca indicação de estresse ambiental. Relaciona-se a menção de fraca indicação de estresse ambiental aos valores negativos de Eh, obtidos em todas as estações, e as concentrações de oxigênio dissolvido ( $\left.<6 \mathrm{mg} \mathrm{L}^{-1}\right)$ obtidas nas estações Ar7 e Ar8. Neste grupo observou-se a presença das espécies Rosalina floridensis e Brizalina striatula. A primeira espécie é epifaunal, comumente observada em ambientes óxicos, com baixos teores de matéria orgânica (Murray, 1991; Martins et al., 2006), a segunda espécie, por sua vez, possui preferências ecológicas inversas (i.e. ambiente enriquecido por matéria orgânica e pobre em oxigênio) (Bernhard e Sen 
Gupta, 1999). Segundo Bouchet et al. (2007), Brizalina striatula sobrevive em sedimentos ricos em matéria orgânica, porém é sensível a depleção de oxigenação.

Ainda não há consenso sobre a utilização da morfometria das carapaças dos foraminíferos bentônicos vivos como um indicativo de qualidade ambiental de ecossistemas bentônicos. De acordo com alguns autores, o tamanho reduzido dos organismos pode refletir antecipação de processos de reprodução, devido a condições favoráveis de disponibilidade de alimento (Bernhard e Reimers, 1991; Diz, Francés, Rosón, 2006), bem como pode representar uma adaptação para sobreviver em ambientes com baixos níveis de oxigenação (Phleger e Soutar, 1973; Boltovskoy, Scott, Medioli, 1991; Kaiho, 1994). Ao contrário de foraminíferos com carapaças grandes, foraminíferos com carapaças pequenas podem sobreviver em ambientes com episódicos períodos de depleção de oxigênio, devido à menor necessidade de oxigênio para suas atividades metabólicas (Bradshaw, 1961; Phleger e Soutar, 1973).

Foraminíferos com carapaças pequenas são positivamente e significantemente relacionados com carbono orgânico, fósforo e nitrogênio. A maior porcentagem de foraminíferos com carapaças pequenas ocorreu na estação $\operatorname{Ar} 10$ (47\%). A estação Ar10 é caracterizada por apresentar baixa densidade, a menor riqueza e elevada abundância de espécies tolerantes a depleção de oxigênio. Nesta estação foram observados os maiores teores de carbono orgânico $(2,19 \%)$, fósforo total $(0,176 \%)$ e enxofre $(0,60 \%)$.

Foraminíferos com carapaças grandes, por sua vez, ocorreram em maior abundância em estações posicionadas na região sudoeste e sul em relação ao trecho difusor do emissário submarino, com padrão de distribuição diretamente oposto ao observado para carbono orgânico $(\mathrm{r}=-0,81 ; p<0,01)$, fósforo total $(\mathrm{r}=-0,86 ; p<0,01)$, enxofre $(\mathrm{r}=-0,75 ; p<0,01)$ e nitrogênio $(\mathrm{r}=-0,57 ; p<$ 0,01). A maior porcentagem ocorreu na estação Ar6, onde foi identificada a maior riqueza, diversidade específica e equitatividade. Nesta estação também ocorreram as maiores abundâncias de espécies epifaunais, bioindicadoras de ambiente bem oxigenado.

Diante do exposto, pode-se inferir que a predominância de carapaças médias e a significativa porcentagem de carapaças pequenas estão associadas a estresse ambiental, ocasionado pela disposição oceânica, cujo aporte crônico de matéria orgânica está causando enriquecimento orgânico e depleção nos níveis de oxigenação na interface água-sedimento.

Em todas as estações analisadas, Ammonia tepida é predominante. Esta espécie euribionte é característica de ambientes costeiros rasos, adaptada a grandes variações ambientais (Bradshaw, 1961; Murray, 1991; Kitazato, 1994). Ammonia tepida é reportada por muitos auto- res como dominante em regiões sob estresse ambiental, onde espécies estenobióticas tendem a diminuir suas densidades ou até mesmo desaparecer (Alve, 1995; Armynot du Châtelet, Debenay, Soulard, 2004; Burone et al., 2006; Ferraro et al., 2006; Lê Cadre e Debenay, 2006). Segundo Debenay e Fernandez (2009), Ammonia tepida é considerada espécie com potencial para biomonitoramentos, principalmente quando se refere a impactos ambientais ocasionados por atividades antrópicas.

A predominância da espécie em áreas sob estresse ambiental deve-se à sua maior capacidade de adaptação e taxa de reprodução, independentemente da fonte causadora das alterações físico-químicas (Alve, 1995; Thomas et al., 2000 [Ammonia beccarii]). No presente estudo, Ammonia tepida está positivamente relacionada aos valores de Eh $(\mathrm{r}=0,67 ; p<0,01)$, o que corrobora sua capacidade de sobreviver em incubação anóxica pelo período aproximado de $24 \mathrm{~h}$ (Bradshaw, 1961). De acordo com resultados obtidos por meio de experimentos laboratoriais, Ammonia tepida é considerada uma espécie anaeróbia facultativa (Bradshaw, 1961; Moodley e Hess, 1992).

As abundâncias relativas de Ammonia tepida obtidas no presente estudo (entre 20 e $49 \%$ ) são indicativas do estresse ambiental que ocorre próximo aos difusores do emissário submarino do Araçá. Debenay e Fernandez (2009), em Sainte Marie Bay, obtiveram abundâncias relativas semelhantes desta espécie (entre 20 e $50 \%$ ), e as relacionaram, em parte, ao aumento de aporte de matéria orgânica lábil por meio de disposição oceânica de esgotos.

\section{CONCLUSÃO}

Os sedimentos próximos ao emissário do Araçá são predominantemente arenosos, com acondicionamento de elevados teores de sedimentos pelíticos na região nordeste, em relação ao trecho difusor. Tal configuração ocorre de acordo com o sentido preferencial das correntes no CSS, que influenciam o transporte e deposição de sedimentos, bem como de matéria orgânica.

O enriquecimento orgânico que ocorre na região é evidenciado, principalmente, pelos teores de fósforo e enxofre, e secundariamente por carbono orgânico total. Infere-se que tal enriquecimento é de origem antrópica, e ocorre devido ao constante aporte de matéria orgânica oriunda do esgoto.

Os baixos níveis de oxigenação da interface água-sedimento são evidenciados pelos valores de Eh e das razões $\mathrm{C} / \mathrm{S}$, sendo que o reflexo pode ser observado tanto na composição das associações, bem como na morfometria das carapaças dos foraminíferos bentônicos.

Observou-se baixa riqueza, com predomínio de espécies detritívoras, bioindicadoras de ambiente enriquecido 
por matéria orgânica, que conforme a Análise de Componentes Principais e índices de correlação de Pearson está associada aos teores de lama, com elevadas concentrações de carbono orgânico total, enxofre, fósforo e nitrogênio.

Os tamanhos das carapaças dos foraminíferos dão suporte aos resultados das análises geoquímicas, ou seja, predominância de carapaças de tamanho médio e pequeno, em regiões de maior aporte de nutrientes e baixas concentrações de oxigênio, e aumento de porcentagens de carapaças grandes em ambiente bem oxigenado, com baixos teores de matéria orgânica. Diante do exposto infere-se que a análise morfométrica pode ser incluída como parâmetro para avaliação de estresse ambiental em ambientes bentônicos.

A dominância de Ammonia tepida, em conjunto com elevada abundância de espécies tolerantes, tais como $B u$ liminella elegantissima, Hopkinsina pacifica e Brizalina striatula reflete o estresse ambiental existente na região estudada, cujo principal fator parece ser o aporte crônico de matéria orgânica por meio do efluente disposto.

\section{AGRADECIMENTOS}

Os autores agradecem a Fundação de Amparo à Pesquisa do Estado de São Paulo (FAPESP), pelo suporte financeiro para a realização das análises contidas neste estudo. Agradecem a CETESB pela doação das amostras de sedimentos e parâmetros físico-químicos da coluna d'água, e ao Centro Universitário Fieo - Unifieo, em especial ao Prof. Dr. Silvio M. Prada, por ter autorizado que os autores realizassem as análises de fósforo no Centro de Estudos Químicos. Os autores também são gratos a Isaac Jamil Sayeg pelas sugestões dadas durante a análise de microscopia eletrônica de varredura (MEV). Gostaríamos de agradecer a dois relatores anônimos, cujas correções e sugestões muito contribuíram para este manuscrito.

\section{REFERÊNCIAS}

ALAVI, S. N. Late Holocene deep-sea benthic foraminifera from Sea of Marmara. Marine Micropaleontology, v. 13, p. 213-237, 1988.

ALTENBACH, A. V.; LUTZE, G. F.; SCHIEBEL, R.; SCHÖNFELD, J. Impact of interrelated and independent ecological controls on benthic foraminifera: an example from the Gulf of Guinea. Palaeogeography, Palaeoclimatology, Palaeoecology, v. 197, p. 213-238, 2003.

ALVE, E. Benthic foraminiferal responses to estuarine pollution: a review. Journal Foraminiferal Research, v. 25 , p. $190-203,1995$.
ALVE, E., BERNHARD, J. M. Vertical migratory response of benthic foraminifera to controlled oxygen concentrations in an experimental mesocosm. Marine Ecology-Progress Series, v. 116, p. 137-151, 1995.

ARMYNOT DU CHÂTELET, E.; DEBENAY, J. P.; SOULARD, R. Foraminiferal proxies for pollution monitoring in moderately polluted harbors. Environmental Pollution, v. 127, p. 27 - 40, 2004.

ASTON, S. R., HEWITT, C. N. Phosphorus and carbon distributions in a polluted coastal environment. Estuarine and Coastal Marine Science, v. 5, p. 243-254, 1977.

BARCELLOS, R. L. Processo sedimentar atual e a distribuição de matéria orgânica sedimentar no Canal de São Sebastião e plataforma continental interna adjacente, 2000. 185 f. Dissertação (Mestrado) - Instituto Oceanográfico, Universidade de São Paulo, 2000.

BARMAWIDJAJA, D. M., Van der ZWAAN, G. J., JÖRISSEN, F. J., PUSKARIC, S. 750 years of eutrophication in the northern Adriatic Sea: evidence from a benthic foraminiferal record. Marine Geology, v. 122, p. 367-384, 1995.

BATURIN, G. N. Phosphorus cycle in the ocean. Lithology and Mineral Resources, v. 38, p. 101-119, 2003.

BERNHARD, J. M.; REIMERS, C. E. Benthic foraminiferal population fluctuations related to anoxia: Santa Barbara Basin. Biogeochemistry, v. 15, p. 127-149, 1991.

BERNHARD, J. M.; SEN GUPTA, B. K. Foraminifera of oxygen-depled environments. In: Sen Gupta, B. K. (Ed.). Modern Foraminifera. Dordrecht: Kluwer Academic, 1999. p. 201-216.

BOLTOVSKOY, E.; GIUSSANI, G.; WATANABE, S.; WRIGHT, R. Atlas of benthic shelf foraminifera of southwest Atlantic. The Hague Boston: W. Junk Hingham, 1980. $147 \mathrm{p}$.

BOLTOVSKOY, E.; SCOTT, D. B.; MEDIOLI, F. S. Morphological variations of benthic foraminiferal testes in response to changes in ecological parameters: a review. Journal of Paleontology, v. 65, p. 175-185, 1991.

BOLTOVSKOY, E. Foraminifera as biological indicator in the study of ocean currents. Departamento de Oceanografia Servício de Hidrografia Naval Buenos Aires, Argentina. Micropaleontology, v. 5, p. 473-481, fig. 1, pls. 1-3, 1959. 
BORDOVSKIY, O. K. Accumulation of organic matter in bottom sediments. Marine Geology, v. 3, p. 33-82, 1965.

BORREGO, J.; LOPES, M.; PENDON, J. G.; MORALES, J. A. C/S ratios is estuarine sediments of the Odiel Rivermouth, S. W. Spain. Journal of Coastal Research, v. 14, p. 1276-1283, 1998.

BOUCHET, V.; DEBENAY, J. P.; SAURIAU, P. G.; RADFORD-KNOERY, J.; SOLETCHNIK, P. Effects of short-term environmental disturbances on living benthic foraminifera during the Pacific oyster summer mortality in the Marennes Oléron Bay (France). Marine Environmental Research, v. 64, p. 358-383, 2007.

BRADSHAW, J. S. Laboratory experiments in the ecology of foraminifera. Contributions from the Cushman Foundation for Foraminiferal Research, v. 12, p. 87-106, 1961.

BURONE, L.; PIRES-VANIN, A. M. S. Foraminiferal assemblages in Ubatuba Bay, south-eastern Brazilian coast. Scientia Matina, v. 70, p. 203-217, 2006.

BURONE, L.; VENTURINI, N.; SPRECHMANN, P.; VALENTE, P.; MUNIZ, P. Foraminiferal responses to polluted sediments in the Montevideo coastal zone, Uruguay. Marine Pollution Bulletin, v. 52, p. 61-73, 2006.

BURONE, L.; VALENTE, P.; PIRES-VANIN, A. M.; SOUSA, S. H. M.; MAHIQUES, M. M.; BRAGA, E. Scientia Marina, v. 71, p. 775-792, 2007.

CABRERA, L. C. Formas de enxofre na coluna d'água e sedimentar numa enseada rasa do estuário da Lagoa dos Patos, 2005. 104 f. Dissertação (Mestrado) - Fundação Universidade do Rio Grande, Oceanografia Física, Química e Geológica, 2005.

CASTRO-FILHO, B. M.; MIRANDA, L. B.; SILVA, L. S.; FONTES, R. F. C.; PREIRA, A. F.; COELHO, A. L. Processos físicos: hidrografia, circulação e transporte. In: PIRES-VANIN, A. M. Oceanografia de um ecossistema subtropical: plataforma de São Sebastião, SP. São Paulo: EDUSP, 2008. p. 57-121.

CEARRETA, A.; IRABIEN, M. J.; LEORRI, E.; YUSTA, I.; QQUINTANILHA, A.; ZABALETA, A. Environmental transformation of the Bilbao estuary, N. Spain: microfaunal and geochemical proxies in the recent sedimentary record. Marine Pollution Bulletin, v. 44, p. 487-503, 2002.
COMPANHA AMBIENTAL DO ESTADO DE SÃO PAULO (CETESB). Relatório de monitoramento de emissário submarino. Série Relatório, Secretaria de Estado do Meio Ambiente, 2007. 116 p. Site: $<$ http://www.cetesb. sp.gov.br/Agua/praias/publicacoes.asp $>$.

CONNEL, D. W.; MILLER, G. J. Chemistry and eCotoxicology of pollution. New York: John Wiley and Son, 1984, $444 \mathrm{p}$.

CONSELHO DE AUTORIDADE PORTUÁRIA (CAP). Plano de Desenvolvimento e Zoneamento do Porto de São Sebastião, São Paulo. Disponível em: $<$ http://www. portodesaosebastiao.com.br/documenta/PDZ-PORTODE-SAOSEBASTIAO-08-09.pdf $>$ Acessado em: 17 de novembro de 2009.

CONSELHO NACIONAL DO MEIO AMBIENTE (CONAMA). Resolução 357 de 2005.

CONTI, L. A. Aplicação de técnicas de geoprocessamento na caracterização de aspectos morfossedimentares do Canal de São Sebastião, litoral norte do estado de São Paulo. 1998. 84 f. Dissertação (Mestrado) - Instituto Oceanográfico, Universidade de São Paulo, São Paulo, 1998.

DE STIGTER, H. C., JORISSEN, E. J., VAN der ZWAAN, G. J. Bathymetric distribution and microhabitat portioning of live (Rose Bengal stained) benthic foraminifera along a shelf to bathial transect in the southern Adriatic Sea. Journal of Foraminiferal Research, v. 28, p. 40-65, 1998.

DEBENAY, J. P.; FERNANDEZ, J-M. Benthic foraminifera records of complex anthropogenic environmental changes combined with geochemical data in a tropical bay of New Caledonia (SW Pacific). Marine Pollution Bulletin, v. 59, p. 311-322, 2009.

DEBENAY, J. P.; ANDRE, O.; BEZIE, S. ; RAMBAUD, $\mathrm{S}$. Foraminifers used as bioindicators in La Turballe harbor (Loire Atlantique, France). In: COASTAL ZONE MONITORING AND MEDIUM TO LONG TERM FORECASTING, FRENCH-JAPANESE INTERNATIONAL SYMPOSIUM, 1997, Paris, October 6-8, Abstracts.

DEBENAY, J. P.; DULEBA, W.; BONETTI, C., SOUZA, S. H. M.; EICHLER, B. Pararotalia cananeiaensis N. SP.: indicator of marine influence and water circulation in Brazilian coast and paralic environments. Journal of Foraminiferal Research, v. 31, p. 152-163, 2001. 
DIZ, P.; FRANCÉS, G.; ROSÓN, G. Effects of contrasting upwelling-downwlling on benthic foraminiferal distribution in the Ría de Vigo (NW Spain). Journal of Marine Systems, v. 60 , p. $1-18,2006$.

DULEBA, W.; DEBENAY, J. P. Hydrodynamic circulation in the estuaries of estação ecológica Juréia-Itatins, Brazil, inferred from foraminifera and thecamoebian assemblages. Journal Foraminiferal Research, v. 33, p. 62-93, 2003.

DULEBA, W.; COIMBRA, J. C.; PETRI, S.; BARBOSA, C. F. Foraminíferos tecamebas e ostracodes recentes utilizados como bioindicadores em estudos ambientais brasileiros. In: SOUSA, C. R. G.; SUGUIO, K.; SANTOS, M.; OLIVEIRA, P. E. (Ed.). Quaternário do Brasil. Ribeirão Preto: Holos, 2005. p. 176-210.

ESTEVES, F. Fundamentos de limnologia. Rio de Janeiro: Interciência, $2^{\mathrm{a}}$. ed. 1998.602 p.

FAGANELLI, J.; MALEJ, A.; PEZDIC. J.; MALACIC, V. C:N:P ratios and stable $\mathrm{C}$ isotopic ratios as indicator of sources of organic matter in the Gulf of Trieste (northern Adriatic). Oceanologia Acta, v. 11, p. 377-382, 1988.

FERRARO, L.; SPROVIERIL, M.; ALBERICO, I.; LIRER, F.; PREVEDELLO, L.; MARSELLA, E. Benthic foraminifera and heavy metals distribution: A case study from de Naples Harbour (Tyrrhenian Sea, Southern Italy). Environmental Pollution, v. 142, p. 274 -287, 2006.

FOLK, R. R.; WARD, W. C. Brazos river bar: study of significance of grain size parameters. Journal of Sedimentary Petrology, v. 17, p. 3-27, 1957.

FONTES, R. F. C. As correntes do Canal de São Sebastião. 1995. 159 f. Dissertação (Mestrado) - Instituto Oceanográfico, Universidade de São Paulo, São Paulo,1995.

FRONTALINI, F.; BUOSI, C.; DA PELO, S.; COCCIONI, R.; CHERCHI, A.; BUCCI, C. Benthic foraminifera as bio-indicators of trace element pollution in the heavily contamined Santa Gilla lagoon (Cagliari, Italy). Marine Pollution Bulletin, v. 58, p. 858-877, 2009.

\section{FUNDAÇÃO DE ESTUDO E PESQUISAS AQUÁTICAS} (FUNDESPA). Levantamento oceanográfico da área diretamente afetada por efluentes dos emissários submarinos de esgotos da SABESP, entre os municípios de São Sebastião e Mongaguá, Estado de São Paulo. São Paulo, 1999, 364 p.
FURTADO, V. V. Sedimentação quaternária no Canal de São Sebastião. Publicação Especial. Instituto Oceanográfico da Universidade de São Paulo, v. 11, p. 27-35, 1995.

FURTADO, V. V.; BARCELLOS, R. L.; CONTI, L. A.; RODRIGUES, M.; MAHIQUES, M. M. Sedimentação. In: PIRES-VANIN, A. M. Oceanografia de um ecossistema subtropical: plataforma de São Sebastião, SP. São Paulo: EDUSP, 2008. p. 141-180.

GROSS, M. G. Carbon determination. In: CARVER, R. E. Procedures in sedimentary petrology. New York: Wiley, 1971. p. 573-596.

GUBitoso, S.; DUlEBA, W; TEODORO, A. C.; PRADA, S. M.; ROCHA, M. M.; LAMPARELLI, C. C.; BEVILACQUA, J. E.; MOURA, D. O. Estudo geoambiental da região circunjacente ao emissário submarino de esgoto do Araçá, São Sebastião (SP). Revista Brasileira de Geociências, v. 38, p. 467-475, 2008.

HERMELIN, J. O. R.; SHIMMIELD, G. B. The importance of the oxygen minimum zone and sediment geochemistry in the distribution of recent benthic foraminifera in the northwest Indian Ocean. Marine Geology, v. 91, p. 1-29, 1990.

JORISSEN, F. J.; BARMAWIDJAJA, D. M.; PUSKARIC, S.; Van der ZWAAN, G. J. Vertical distribution of benthic foraminifera in the northern Adriatic Sea, the relation with the organic flux. Marine Micropaleontology, v. 19, p. 131-146, 1992.

KAIHO, K. Benthic foraminiferal dissolved-oxygen index and dissolved-oxygen levels in the modern ocean. Geology, v. 22, p. 719-722, 1994.

KITAZATO, H. Foraminiferal microhabitats in four marine environments around Japan. Marine Micropaleontology, v. 24, p. 29-41, 1994.

LASSEN, R.; TJELL, J. C.; HANSE, J. A. Phosphorus recovery from sewage for agriculture. Waste Management and Research, v. 2, p. 369-378, 1984.

LÊ CADRE, V.; DEBENAY, J. P. Morphological and cytological responses of Ammonia (foraminifera) to cooper contamination: Implications for the use of foraminifera as bioindicators of pollution. Environmental Pollution, v. 143 , p. $304-317,2006$. 
LEGG, J. O.; BLACK, C. A. Determination of organic phosphorus in soils: II. Ignition method. Soil Science Society of America Proceedings, v. 19, p. 139-143, 1955.

LINKE, P.; LUTZE, G. F. Microhabitat preferences of benthic foraminífera - a static concept or a dynamic adaptation to optimize food acquisition? Marine Micropaleontology, v. 20, p. 215-234, 1993.

LUTZE, G. F.; COULBOURN, W. T. Recent benthic foraminifera from the continental margin of Northwest Africa: community structure and distribution. Marine Micropaleontology, v. 8, p. 361-401, 1984.

LYONS, T. W.; BERNER, R. A. Carbon-sulfur-iron systematics of the uppermost deep-water sediments of the Black Sea. Chemical Geology, v. 99, p. 1-27, 1992.

MARCELlinO, E. B. Sistematização dos projetos de emissários submarinos da SABESP e avaliação de desempenho através do modelo computacional CORMIX. 2000, 272 f. Dissertação (Mestrado)-Universidade de São Paulo, Escola Politécnica, São Paulo, 2000.

MARTINS, V.; DUBERT, J.; JOUANNEAU, J-M.; WEBER, O.; SILVA, E. F.; PATINHA, C.; DIZ, J. M. A.; ROCHA, F. A multiproxy approach of the Holocene evolution of shelf-slope circulation on the NW Iberian Continental Shelf. Marine Geology, v. 239, p. 1-18, 2007.

MARTINS, V. ; JOUANNEAU, J. M., WEBER, O., ROCHA, F. Tracing the late Holocene evolution of the NW Iberian upwelling system. Marine Micropaleontology, v. 59, p. 35-55, 2006.

MIRANDA, L. B.; CASTRO-FILHO, B. M. Variabilidade da circulação e do transporte de volume no Canal de São Sebastião (SP). Publicação Especial do Instituto Oceanográfico, v. 11, p. 1-9, 1995.

MITSCH, W. J.; GOSSELINK, J. G. Wetlands. New York: Van Nostrand Reinhol, 1986. 539 p.

MOJTAHID, M.; JORISSEN, F.; PEARSON, T. H. Comparison of benthic foraminiferal and macrofaunal responses to organic pollution in the Firth of Clyde (SCotland). Marine Pollution Bulletin, v. 56, p. 42-76, 2008.

MOODLEY, L., HESS, C. Tolerance of infaunal benthic foraminifera for low and high oxygen concentrations. Biological Bulletin, v. 183, p. 94-98, 1992.
MURRAY, J. W. Ecology and paleoecology of benthic foraminifera. London: Longman Scientific and Technical, $1991.397 \mathrm{p}$.

MURRAY, J. W. Foraminiferal assemblage formation in depositional sinks on the continental shelf west of SCotland. Journal of Foraminiferal Research, v. 33, p. 101-121, 2003.

NAGAI, R. H., SOUSA, S. H. M., BURONE, L., MAHIQUES, M. M. Paleoproductivity changes during the Holocene in the inner shelf of Cabo Frio, southeaster Brazilian continental margin: Benthic foraminifera and sedimentological proxies. Quaternary International, v. 206, p. 62-71, 2009.

NAGAI, R. H., SOUSA, S. H. M.; LOURENÇO, R. A.; BÍCEGO, M. C.; MAHIQUES, M. M. Paleoproductivity changes during the late quaternary in the Southeastern Brazilian upper continental margin of the Southwestern Atlantic. Brazilian Journal of Oceanography, v. 58, p. 31-41, 2010.

NIGAN, R.; SARASWAT, R.; PANCHANG, R. Application of foraminifers in eCotoxicology: Retrospect, perspect and prospect. Environment International, v. 32, p. $273-283,2006$.

OZÓRIO, V. K. L., OLIVEIRA, W. Polifosfatos em detergentes em pó comerciais. Química Nova, v. 24, p. 700-708, 2001.

PHLEGER, F. B.; SOUTAR, A. Production of benthic foraminifera in three east Pacific oxygen minima. Micropaleontology, v. 19, p. 110-115, 1973.

PIELOU, E. C. The measurement of diversity in different types of biological collections. Journal of Theorical Biology, v. 13, p. 131-144, 1969.

RESIG, J. M. Foraminiferal ecology around ocean outfalls of southern Califórnia. Waste disposal in the marine environment. London: Pergamon Press, 1960. p. 104-121.

SCHÖNFELD, J. Recent benthic foraminiferal in deep high-energy environments from the Gulf of Cadiz (Spain). Marine Micropaleontology, v. 44, p. 141-162, 2002.

SHANNON, C. E. The mathematical theory of communication. Urbana: University of Illinois Press, 1948. $117 \mathrm{p}$. 
SHEPARD, F. P. Nomenclature based on sand-siltclay ratios. Journal Sedimentary Petrology, v. 24, p. 151-158, 1954.

SILVA, L. S.; MIRANDA, L. B.; CASTRO, B. M. Oceanografia da plataforma interna de São Sebastião (OPISS). Subprograma Oceanografia Física. Relatório Técnico do Instituto Oceanográfico, v. 47, p. 1-31, 2001.

SOARES-GOMES, A.; FIGUEIREDO, A. G. O ambiente marinho. In: PEREIRA, R. C.; SORES-GOMES, A. (Ed.). Biologia Marinha. Rio de Janeiro: Interciência, 2002. 382 p.

STEIN, R. Accumulation of organic carbon in marine sediments. Results from the Deep Sea Drilling Project/Ocean Drilling Program. In: BHATTACHARJI, S.; FRIEDMAN, G. M.; NEUGEBAUER, H. J.; SEILACHER, A. Lecture Notes in Earth Sciences. Berlin: Springer, 1991, 217 p.

SUGUIO, K. Introdução à Sedimentologia. São Paulo: Edgard Blücher/EDUSP, 1973. 317 p.

SUTHERLAND, T. F.; LEVINGS, C. D.; PETERSEN, S. A.; PIERCEY, B. The use of meiofauna as an indicator of benthic organic enrichment associated with salmonid aquaculture. Marine Pollution Bulletin, v. 54, p. 1249-1261, 2007.

THOMAS, E.; GAPOTCHENKO, T.; VAREKAMP, J. C.; MECRAY, E. L.; BUCHHOLZ TEN BRINK, M. R. Benthic foraminifera and environmental changes in Long Island Sound. Journal of Coastal Research, v. 16, p. 641-655, 2000.

TUREKIAN, K. K.; WEDEPOHL, K. H. Distribution of the Elements in some major units of the Earth's crust. Geological Society of America Bulletin, v. 72, 175 p, 1961.

TYSON, R. V.; PEARSON, T. H. Modern and ancient continental shelf anoxia. Geological Society of London Special Publication, 1991, 474 p.

Van der ZWAAN, G. J.; JORISSEN, F. J. Biofacial patterns in river-induced shelf anoxia. London: G. S., 1991. p. 65-82. (Geological Society Special Publication, 58).

WALTON, W. R. 1952. Techniques for recognition of living foraminifera. Contribution of Cushman Foundation for Foraminiferal Research, v. 3, p. 56-60, 1952.

WARD, J. N.; POND, D. W.; MURRAY, J. W. Feeding of benthic foraminifera on diatoms and sewage-derived organic mater: an experimental application of lipid biomarker techniques. Marine Environmental Research, v. 56, p. 515-530, 2003.

WENTWORTH, C. K. A scale of grade and class terms for clastics sediments. Journal of Geology, v. 30, p. 377-392, 1922.

WETZEL, R. G.; LIKENS, G. E. Limnological analyses. New York: Springer-Verlag, 1991. 391 p.

WILLIAMSON, M. A. Recent foraminiferal diversity on the continental margin of Nova SCotia, Canada. Journal of Foraminiferal Research, v. 15, p. 43-51, 1985.

YANKO, V.; KRONFELD, J.; FLEXER, A. Response of benthic foraminifera to various pollution sources: implications for pollution monitoring. Journal of Foraminiferal Research, v. 24, p 1-17, 1994.

ZAGATTO, E. A. G.; JACINTHO, A. O.; REIS, B. F.; KRUG, F. J.; BERHGAMIN FILHO, H.; PESSENDA, L. C. R.; MORTATTI, J.; GINÉ, M. F. Manual de análises de plantas e águas empregando sistemas de injeção em fluxo. Piracicaba: Universidade de São Paulo, CENA/Seção de Química Analítica, 1981, 45 p.

ZALESNY, E. R. Foraminiferal ecology of Santa Monica Bay, California. Micropaleontology, v. 5, p. 101-126, 1959. 


\section{APÊNDICES}

Apêndice 1.1. Espécies bioindicadoras de ambiente enriquecido por matéria orgânica.

As espécies pertencentes a este grupo são espécies dominantes em ambientecom baixos níveis de oxigenação e enriquecidos organicamente. Apesar dos gêneros Bolivinídeos e Bumininídeos serem reportados em ambientes óxicos (Debenay et al., 1997, 2001; Bouchet et al., 2007), tais gêneros sobrevivem no interior de camadas de sedimento com depleção de oxigênio, e podem sobreviver em anóxicas condições por longos períodos de tempo (Moodleye Hess, 1992). Bolivina ordinaria (Hermelin e Shimmield,1990; Martins et al., 2007); Brizalina striatula (Lutze e Coulbourn, 1984; Bernhard e Sen Gupta, 1999; Martins et al., 2006); Bolivina cf. sphatulata (Alavi, 1988; de Stigter, Jorissen, van der Zwaan, 1998; Martins et al., 2006); Bulimina marginata (Alavi, 1988; Alve e Bernhard, 1995; Bernhard e Sen Gupta, 1999; van der Zwaan e Jorissen, 1991; Burone e PiresVanin, 2006; Martins et al., 2006; Nagai et al., 2009, Nagai et al., 2010), Buliminella elegantissima (Bernhard e Sen Gupta, 1999; Burone e Pires-Vanin, 2006); Pseudononion atlanticum (Burone e Pires-Vanin, 2006; Nagai et al., 2009); Cassidulina crassa f. media (Alavi, 1988; Bernhard e Sen Gupta, 1999), Fursenkoina pontoni (Bernhard e Sen Gupta, 1999); Trochammina spp. (Schönfeld, 2002).

Apêndice 1.2. Espécies bioindicadoras de ambiente bem oxigenado.

Este grupo é composto por espécies frequentemente observadas em ambientes bentônicos bem oxigenados, com forte hidrodinamismoe baixos teores de nutrientes, tais como Gavelinopsis praegeri (Altenbach et al., 2003; Duleba et al., 2005; Martins et al., 2006), Discorbis williamsoni (Nagai et al., 2009; Murray, 1991; Linke e Lutze, 1993); Hanzawaia boueana (Barmawidjaja et al., 1995 [as Hanzawaia concentrica]; Duleba et al., 2005); Lobatula lobatula (Williamson, 1985); Lepidoteuramina ochracea (Martins et al., 2006; Murray, 1991); Quinqueloculina spp. (Kaiho, 1994; Martins et al., 2006; Nagai et al., 2009); Rosalina floridana (Martins et al., 2006; Dulebaet al., 2005; Murray, 1991); Neocornobina terquemi (Duleba et al., 2005; Murray, 1991), Patelina corrugata (Martins et al., 2006; Murray, 1991), Cibicides spp. (Kaiho, 1994; Altenbach et al., 2003 [as Cibicides gerthi]; Duleba et al., 2005). 
Apêndice 2. Abundância relativa das espécies de foraminíferos bentônicos vivos identificados próximo ao emissário submarino da Baía do Araçá.

\begin{tabular}{|c|c|c|c|c|c|c|c|c|c|c|}
\hline Estações & Ar1 & Ar2 & Ar3 & Ar4 & Ar5 & Ar6 & Ar7 & Ar8 & Ar9 & Ar10 \\
\hline Adelosina sp. & 0,0 & 0,0 & 1,0 & 0,0 & 0,0 & 0,0 & 0,0 & 0,0 & 0,0 & 0,0 \\
\hline Ammonia parkinsoniana & 5,9 & 4,4 & 2,9 & 5,0 & 3,9 & 0,7 & 2,7 & 2,5 & 9,6 & 0,0 \\
\hline Ammonia tepida & 44,9 & 41,6 & 49,0 & 44,6 & 45,9 & 20,0 & 43,8 & 41,4 & 37,6 & 39,6 \\
\hline Ammonia spp. & 4,2 & 1,5 & 1,0 & 0,0 & 9,5 & 7,9 & 0,0 & 1,5 & 1,5 & 2,0 \\
\hline Ammotium morenoi & 0,8 & 1,5 & 1,0 & 0,0 & 0,0 & 0,0 & 0,9 & 1,5 & 0,5 & 0,0 \\
\hline Angulogerina angulosa & 0,0 & 0,0 & 0,0 & 0,8 & 0,0 & 0,0 & 0,0 & 0,0 & 0,0 & 0,0 \\
\hline Astrononion sp. & 0,0 & 0,0 & 0,0 & 0,0 & 0,0 & 0,7 & 0,0 & 0,0 & 0,0 & 0,0 \\
\hline Aubignyna planidorso & 0,0 & 0,0 & 0,0 & 0,0 & 0,0 & 0,0 & 0,0 & 0,0 & 1,0 & 0,0 \\
\hline Bolivina cf. sphatula & 1,7 & 1,5 & 0,0 & 0,8 & 0,0 & 0,0 & 0,0 & 0,0 & 0,0 & 0,0 \\
\hline Bolivina compacta & 0,0 & 0,7 & 1,0 & 0,8 & 0,4 & 2,1 & 0,0 & 1,0 & 1,0 & 2,0 \\
\hline Bolivina doniezi & 0,8 & 2,2 & 2,0 & 0,8 & 0,0 & 1,4 & 0,0 & 2,0 & 2,0 & 5,0 \\
\hline Bolivina ordinaria & 2,5 & 1,5 & 1,0 & 0,8 & 0,0 & 0,0 & 3,6 & 1,5 & 3,0 & 1,0 \\
\hline Bolivina plicata & 1,7 & 0,0 & 0,0 & 0,8 & 0,0 & 2,9 & 1,8 & 0,0 & 2,0 & 0,0 \\
\hline Bolivina translucens & 0,0 & 0,0 & 0,0 & 0,0 & 0,0 & 0,0 & 1,8 & 0,0 & 0,0 & 0,0 \\
\hline Bolivina sp. & 0,8 & 0,0 & 0,0 & 3,3 & 3,1 & 0,0 & 2,7 & 0,0 & 1,0 & 3,0 \\
\hline Brizalina striatula & 4,2 & 4,4 & 8,8 & 8,3 & 3,1 & 12,9 & 6,3 & 6,6 & 3,6 & 3,0 \\
\hline Bulimina marginata & 0,8 & 4,4 & 3,9 & 1,7 & 0,8 & 0,7 & 0,9 & 1,0 & 1,0 & 5,0 \\
\hline Bulimina elongata & 0,8 & 0,0 & 0,0 & 0,0 & 0,4 & 0,0 & 0,0 & 1,0 & 1,0 & 0,0 \\
\hline Bulimina sp. & 0,0 & 0,0 & 1,0 & 1,7 & 0,4 & 0,0 & 0,0 & 0,0 & 0,0 & 0,0 \\
\hline Buliminella elegantissima & 0,8 & 8,8 & 5,9 & 6,6 & 5,1 & 1,4 & 3,6 & 2,0 & 9,1 & 5,9 \\
\hline Cassidulina crassa f.media & 0,0 & 2,9 & 1,0 & 2,5 & 0,0 & 0,7 & 2,7 & 5,1 & 3,6 & 3,0 \\
\hline Cassidulina laevigata & 0,0 & 0,0 & 0,0 & 0,0 & 0,0 & 0,0 & 0,0 & 0,5 & 0,0 & 0,0 \\
\hline Cassidulina subglobosa & 0,0 & 0,0 & 0,0 & 0,0 & 0,4 & 0,0 & 0,9 & 0,5 & 0,5 & 4,0 \\
\hline Cibicides refulgens & 0,0 & 0,0 & 0,0 & 0,0 & 0,0 & 0,7 & 0,0 & 0,0 & 0,5 & 0,0 \\
\hline cibicides variabilis & 0,0 & 2,2 & 0,0 & 0,0 & 0,0 & 1,4 & 0,0 & 1,0 & 0,0 & 0,0 \\
\hline Cibicides sp. & 0,0 & 0,0 & 3,9 & 0,0 & 0,4 & 0,7 & 0,9 & 2,0 & 0,0 & 0,0 \\
\hline Cornuspira involvens & 0,8 & 0,0 & 0,0 & 0,0 & 0,0 & 0,7 & 0,0 & 0,5 & 0,0 & 0,0 \\
\hline Discorbis bertheloti & 0,0 & 0,0 & 1,0 & 0,0 & 0,0 & 0,7 & 0,0 & 0,0 & 0,0 & 0,0 \\
\hline Discorbis williamsoni & 0,0 & 0,0 & 0,0 & 0,0 & 0,0 & 0,7 & 0,0 & 0,0 & 0,0 & 0,0 \\
\hline Cribroelphidium discoidale & 0,0 & 0,0 & 0,0 & 0,0 & 0,4 & 0,7 & 0,0 & 0,0 & 0,0 & 0,0 \\
\hline Cribroelphidium galvestonense & 0,0 & 0,0 & 0,0 & 0,0 & 0,4 & 0,0 & 0,0 & 0,0 & 0,0 & 0,0 \\
\hline Cribroelphidium excavatum & 0,8 & 0,0 & 1,0 & 1,7 & 2,0 & 1,4 & 0,9 & 0,5 & 0,0 & 1,0 \\
\hline Eponides rephandus & 0,0 & 0,0 & 1,0 & 0,0 & 0,0 & 0,0 & 0,0 & 0,0 & 0,0 & 0,0 \\
\hline Fissurina laevigata & 0,0 & 0,0 & 0,0 & 0,0 & 0,4 & 0,7 & 0,9 & 0,0 & 0,0 & 1,0 \\
\hline Fursenkoina pontoni & 0,0 & 0,7 & 0,0 & 0,0 & 1,6 & 0,7 & 4,5 & 0,0 & 1,0 & 0,0 \\
\hline Gaudryina exilis & 7,6 & 2,9 & 0,0 & 0,0 & 3,9 & 0,7 & 1,8 & 1,5 & 0,5 & 1,0 \\
\hline
\end{tabular}


Apêndice 2. (continuação)

\begin{tabular}{|c|c|c|c|c|c|c|c|c|c|c|}
\hline Estações & Ar1 & Ar2 & Ar3 & Ar4 & Ar5 & Ar6 & Ar7 & Ar8 & Ar9 & Ar10 \\
\hline Gavelinopsis praegeri & 1,7 & 0,0 & 0,0 & 0,0 & 0,8 & 2,9 & 0,9 & 1,5 & 0,0 & 0,0 \\
\hline Hanzawaia boueana & 0,0 & 0,0 & 0,0 & 0,0 & 0,0 & 2,9 & 0,0 & 1,0 & 0,0 & 0,0 \\
\hline Haynesina germanica & 0,0 & 0,0 & 0,0 & 0,8 & 0,8 & 0,0 & 0,0 & 1,5 & 0,0 & 0,0 \\
\hline Hopkinsina pacifica & 0,8 & 5,1 & 4,9 & 4,1 & 2,0 & 4,3 & 3,6 & 4,0 & 8,6 & 5,9 \\
\hline Lagena striata & 0,0 & 0,7 & 0,0 & 0,0 & 0,0 & 0,0 & 0,0 & 0,0 & 0,0 & 0,0 \\
\hline Lenticulina sp. & 0,0 & 0,7 & 0,0 & 0,0 & 0,0 & 0,0 & 0,0 & 0,0 & 0,5 & 0,0 \\
\hline Lepidoteuramina ochracea & 0,8 & 0,0 & 0,0 & 0,0 & 0,0 & 0,7 & 0,0 & 1,0 & 1,0 & 0,0 \\
\hline Leptohalysis catella & 0,8 & 0,7 & 0,0 & 0,0 & 1,6 & 0,7 & 0,0 & 0,5 & 0,0 & 0,0 \\
\hline Lobatula lobatula & 1,7 & 2,2 & 1,0 & 0,0 & 0,0 & 1,4 & 0,9 & 1,0 & 0,0 & 1,0 \\
\hline Melonis sp. & 0,0 & 0,0 & 0,0 & 0,0 & 0,0 & 0,0 & 0,9 & 0,0 & 0,0 & 0,0 \\
\hline Miliolinela subrotunda & 2,5 & 0,7 & 0,0 & 0,0 & 0,0 & 0,0 & 0,0 & 0,0 & 0,0 & 0,0 \\
\hline Neocornobina terquemi & 0,0 & 0,7 & 1,0 & 0,8 & 0,4 & 1,4 & 0,9 & 1,5 & 1,0 & 2,0 \\
\hline Pararotalia cananeiaensis & 0,8 & 0,0 & 2,9 & 2,5 & 2,7 & 0,7 & 0,0 & 1,0 & 0,0 & 3,0 \\
\hline Patelina corrugata & 0,0 & 0,0 & 0,0 & 0,0 & 0,0 & 3,6 & 0,0 & 0,0 & 0,0 & 0,0 \\
\hline Protochista findens & 0,8 & 2,2 & 0,0 & 0,0 & 0,0 & 0,0 & 0,0 & 0,0 & 0,5 & 0,0 \\
\hline Pseudononion atlanticum & 1,7 & 1,5 & 0,0 & 4,1 & 2,7 & 5,0 & 3,6 & 4,5 & 3,0 & 4,0 \\
\hline Pseudononion pauperatus & 0,0 & 0,0 & 0,0 & 0,0 & 0,0 & 0,7 & 0,0 & 0,0 & 0,0 & 0,0 \\
\hline Rosalina floridensis & 5,9 & 1,5 & 1,0 & 0,8 & 0,0 & 7,1 & 1,8 & 2,5 & 0,0 & 2,0 \\
\hline Quinqueloculina brodermani & 0,0 & 0,0 & 0,0 & 0,0 & 0,0 & 0,0 & 0,9 & 0,0 & 0,0 & 0,0 \\
\hline Quinqueloculina milletti & 1,7 & 0,7 & 1,0 & 0,0 & 0,0 & 2,9 & 0,0 & 0,5 & 0,0 & 1,0 \\
\hline Quinqueloculina lamarckiana & 0,0 & 0,0 & 0,0 & 0,8 & 0,0 & 0,0 & 0,0 & 0,0 & 0,0 & 0,0 \\
\hline Quinqueloculina laevigata & 0,0 & 0,0 & 0,0 & 0,0 & 0,0 & 0,7 & 0,0 & 0,5 & 0,0 & 0,0 \\
\hline Quinqueloculina stalkeri & 0,0 & 0,0 & 0,0 & 0,0 & 0,0 & 0,7 & 0,0 & 0,0 & 0,5 & 0,0 \\
\hline Spirobolivina sp. & 0,0 & 0,0 & 0,0 & 1,7 & 0,0 & 0,0 & 0,0 & 1,0 & 1,0 & 0,0 \\
\hline Stanphortia fusiformis & 0,0 & 0,0 & 0,0 & 0,0 & 0,4 & 0,0 & 0,0 & 0,0 & 0,0 & 0,0 \\
\hline Textularia aglutinans & 0,0 & 0,0 & 0,0 & 0,0 & 0,0 & 0,0 & 0,0 & 0,5 & 0,0 & 0,0 \\
\hline Textularia earlandi & 0,0 & 0,7 & 0,0 & 0,8 & 2,7 & 0,0 & 0,0 & 0,0 & 0,0 & 1,0 \\
\hline Triloculins cultrata & 0,0 & 0,0 & 0,0 & 0,8 & 0,0 & 0,0 & 0,0 & 0,0 & 0,0 & 0,0 \\
\hline Triloculina laevigata & 0,0 & 0,0 & 0,0 & 0,0 & 0,0 & 0,0 & 1,8 & 1,0 & 0,0 & 0,0 \\
\hline Triloculina oblonga & 0,0 & 0,0 & 0,0 & 0,0 & 0,0 & 1,4 & 0,9 & 0,0 & 0,0 & 0,0 \\
\hline Trochammina sp. & 0,0 & 0,0 & 0,0 & 0,0 & 0,0 & 0,7 & 0,9 & 0,5 & 0,0 & 0,0 \\
\hline Virgulinella fragilis & 0,0 & 0,0 & 0,0 & 0,0 & 0,0 & 0,0 & 0,0 & 0,0 & 0,0 & 1,0 \\
\hline Não identificado & 0,0 & 0,7 & 2,0 & 0,8 & 3,1 & 0,0 & 0,9 & 0,0 & 3,0 & 3,0 \\
\hline Densidade (foraminíferos $/ \mathrm{cm}^{3}$ ) & 3 & 7 & 5 & 6 & 25 & 7 & 6 & 10 & 10 & 5 \\
\hline Volume de sedimento analisado & 40 & 20 & 20 & 20 & 10 & 20 & 20 & 20 & 20 & 20 \\
\hline Riqueza & 25 & 26 & 20 & 23 & 25 & 36 & 26 & 34 & 24 & 21 \\
\hline Diversidade específica $\left(\mathrm{H}^{\prime}\right)$ & 2,35 & 2,45 & 2,13 & 2,31 & 2,32 & 3,13 & 2,46 & 2,64 & 2,45 & 2,47 \\
\hline Equitatividade & 0,72 & 0,75 & 0,71 & 0,74 & 0,72 & 0,87 & 0,76 & 0,74 & 0,76 & 0,81 \\
\hline
\end{tabular}

